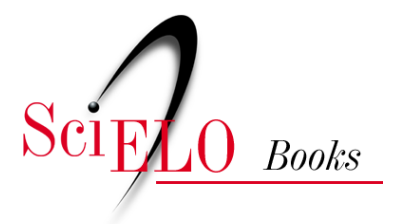

\title{
5. Educação, raça e riqueza
}

\author{
Emerson Ferreira Rocha
}

\section{SciELO Books / SciELO Livros / SciELO Libros}

ROCHA, E.F. Educação, raça e riqueza. In: O negro no mundo dos ricos: um estudo sobre a disparidade racial de riqueza com os dados do Censo 2010 [online]. Brasília: Editora UnB, 2019, pp. 111-163. Pesquisa, inovação \& ousadia series. ISBN: 978-65-5846-052-7. https://doi.org/10.7476/9786558460527.0007.

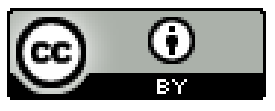

All the contents of this work, except where otherwise noted, is licensed under a Creative Commons Attribution 4.0 International license.

Todo o conteúdo deste trabalho, exceto quando houver ressalva, é publicado sob a licença Creative Commons Atribição 4.0.

Todo el contenido de esta obra, excepto donde se indique lo contrario, está bajo licencia de la licencia Creative Commons Reconocimento 4.0. 


\section{Educação, raça e riqueza}

Foi mostrado que existe desigualdade racial na riqueza tanto em termos de composição quanto de nível. Em outras palavras, não apenas os negros são minoria entre os ricos (desigualdade de composição), mas, entre os ricos, os negros contam com um nível de renda menor. Notou-se isso por meio da medida de riqueza proposta por Medeiros (2005), que pode assumir diferentes graus de sensibilidade nas rendas mais elevadas. O que se verificou é que quanto maior essa sensibilidade, maior a proporção de riqueza acumulada pelos brancos, segundo a decomposição da medida por grupos raciais, mostrando que os brancos são os mais ricos entre os ricos. Sendo assim, as evidências até aqui levantadas apontam para a possibilidade de se abordar a desigualdade racial de riqueza sob dois ângulos: (a) a desigualdade em termos de quem participa do grupo dos $1 \%$ mais ricos e (b) a desigualdade racial no interior desse grupo. No presente contexto, contudo, serão concentrados esforços no primeiro aspecto. O segundo não pode ser explorado a contento no contexto do presente estudo, pelo menos não de um ponto de vista explicativo, porque a variação da renda dentro do grupo dos ricos não responde a mecanismos que possam ser minimamente captados pelas informações disponíveis. Este último aspecto merece uma explicação mais detida.

A educação é um dos principais fatores associados à riqueza. Principalmente quando se considera a educação superior não como uma única categoria de nível educacional, mas em termos das diferentes áreas de formação, é nítida a relação 
existente entre determinadas formações superiores e a chance de se estar entre os 1\% mais ricos. Além disso, parte considerável da desigualdade racial de renda é explicada por desigualdades educacionais. Será, então, que o mesmo se aplica à desigualdade racial interna ao grupo dos ricos? Sem embargo, tudo o que explica a desigualdade de renda ao longo da sua distribuição é suspeito de explicar também a desigualdade entre os ricos, já que a riqueza não é senão um aspecto particular da distribuição de renda. Mas as coisas não são tão simples. Quando se muda o foco das posições mais centrais para um dos seus extremos, surgem diferenças importantes nos processos subjacentes à distribuição dos rendimentos. A consequência disso é que as informações disponíveis para esse estudo, que permitem uma abordagem explicativa satisfatória da distribuição de renda na população como um todo, não se prestam a um estudo adequado da desigualdade racial apenas entre os mais ricos. Do ponto de vista do que se observa com o Censo Demográfico, a variação de renda entre os ricos se comporta de modo muito pouco sistemático.

Com efeito, desigualdades educacionais, segmentação regional, segmentação entre zonas rurais e urbanas, assim como o avanço do curso de vida indicado pela idade, explicam uma porção menor dos rendimentos dos 1\% mais ricos. Em regressões lineares que utilizam esses fatores para explicar a variação da renda, os resíduos, ou seja, a porção das rendas individuais que não é explicada por tais variáveis, são consideravelmente maiores entre os mais ricos. Isso é mostrado por Medeiros (2005) e também verificado aqui, onde se encontra um coeficiente de correlação de Pearson da ordem de 0,41 entre os rendimentos e o módulo, ou seja, a magnitude, independentemente do sinal, dos resíduos. Essa medida revela que há uma associação positiva considerável entre os níveis de rendimento e o tamanho dos resíduos, isto é, que quanto maiores os rendimentos, menos os fatores considerados explicam a sua variação. Embora esses resultados sejam em parte explicados pela própria modelagem por regressão linear, eles apontam também para uma redução do poder explicativo das variáveis consideradas em se tratando dos rendimentos mais altos. Medeiros e Galvão (2016), por exemplo, procuraram analisar a variação de renda 
entre os ricos a partir da desigualdade educacional com base nos dados do Censo Demográfico 2010, e concluíram que a educação explica pouco essa variação.

São, certamente, várias as mudanças nos mecanismos subjacentes que determinam a distribuição de renda quando se passa a tratar exclusivamente do grupo dos ricos. A estrutura ocupacional encerra uma das principais mudanças em jogo. Obviamente, a distribuição de renda é, em grande medida, explicada pela distribuição das pessoas em diferentes categorias ocupacionais. Para qualquer conjunto de categorias ocupacionais agregadas que se adote como representação da estrutura ocupacional, haverá variação de renda tanto no interior dessas ocupações quanto entre elas. A variação dentro das ocupações responde a uma série de fatores, como relações de autoridade, atributos individuais, segmentação regional e outra série de ponderáveis e de imponderáveis. A variação de renda entre as ocupações, por sua vez, tende a constituir, por excelência, um processo mais estável de distribuição dos rendimentos. Não há dúvidas de que a relação entre níveis educacionais, por um lado, sobretudo em se tratando de credenciais, e a renda, por outro lado, tem na estrutura ocupacional um mecanismo fundamental de mediação.

Considere-se, a título de um breve exercício, uma representação da estrutura ocupacional com 43 ocupações, seguindo de perto as agregações sugeridas pela própria Classificação de Ocupações para Pesquisas Domiciliares utilizada para o Censo 2010. De acordo com Gibbons et al. (2012), pode-se distinguir a variação sistemática nos rendimentos entre ocupações por meio de regressões lineares dos rendimentos. Para tanto, subtrai-se do coeficiente de determinação (proporção da variância explicada) de um modelo contendo indicadores de características individuais e também da posição ocupacional das pessoas, pela mesma medida obtida, porém, por um modelo contendo apenas indicadores para as características individuais. Considerando o total da população em estudo, uma regressão contendo variáveis para educação (com o nível superior desagregado em áreas de formação), idade e ocupações explica 38,4\% da variação nos logaritmos dos rendimentos. Quando se excluem as categorias ocupacionais do modelo, esse valor desce para $28,1 \%$, 
indicando, portanto, que a estrutura ocupacional responde por aproximadamente $10 \%$ da variação total dos rendimentos e por algo em torno de $27 \%$ da sua variação sistemática, no sentido de respondente aos fatores explicativos considerados no modelo mais completo. Ainda seguindo as orientações de Gibbons et al. (2012), essas cifras devem ser consideradas uma medida conservadora da relevância das ocupações para a variação sistemática dos rendimentos, já que, pela educação estar correlacionada às posições ocupacionais, os indicadores educacionais captam parte dos efeitos das ocupações quando essas são excluídas do modelo. Sendo assim, conclui-se que a perda de variabilidade entre ocupações pode reduzir a variação sistemática dos rendimentos em torno de $27 \%$. Isso numa estimativa conservadora.

Sem dúvidas, esse fato afeta o estudo da desigualdade de renda entre os mais ricos. Considerando as 43 categorias ocupacionais consideradas, aproximadamente $70 \%$ dos $1 \%$ mais ricos concentram-se em apenas seis delas. Colocando em palavras, a diversidade ocupacional entre os mais ricos é consideravelmente menor e, com isso, perde-se em variação sistemática dos rendimentos e, portanto, em capacidade explicativa. Isso não quer dizer, necessariamente, que a distribuição de renda entre os 1\% mais ricos seja, em si, assistemática. É razoável admitir que fatores como transmissão intergeracional de patrimônio, não observados pelo Censo, respondam por parte considerável da variação dos rendimentos entre os mais ricos. Tão razoável quanto é admitir a relevância da herança imaterial sob a forma de habilidades e de recursos sociais estratégicos. Diferenças na qualidade e no prestígio da instituição de ensino, dados também não observados pelos levantamentos nacionais, como Censo e PNAD, constituem outros fatores relevantes. Resumindo a trama: quando se passa ao extremo mais rico da distribuição, alteram-se a natureza e o impacto dos mecanismos subjacentes que imprimem sistematicidade à variação dos rendimentos, e as informações disponíveis no Censo não fazem bom um serviço quanto à captação desses mecanismos especificamente.

Diante desses fatos, o presente estudo se debruça sobre a desigualdade racial na composição do grupo dos ricos, deixando de lado a já constatada desigualdade 
racial em níveis de renda no interior desse grupo, sobre a qual pouco se poderia dizer do ponto de vista explicativo. O objetivo é investigar a desigualdade racial que existe na probabilidade de ser rico. Apenas 0,6\% dos negros estão entre os $1 \%$ mais ricos, comparado a 2,65\% dos brancos. Em outras palavras, a probabilidade de uma pessoa negra ser rica equivale a aproximadamente $22 \%$ da probabilidade de uma pessoa branca o ser. O que explica essa disparidade? Sabe-se que a educação medeia uma porção substancial da desigualdade racial de renda. Será que o mesmo acontece com a disparidade racial de riqueza? Além disso, é de se esperar que as diferenças em termos de área de formação superior assumam um papel especial na determinação das chances de riqueza. Também é possível que determinado nível educacional, incluindo diferenças nas áreas de formação, não se convertam em chances de riqueza de maneira equânime para negros e brancos.

As fontes da disparidade racial de riqueza podem ser organizadas em três grupos. No primeiro, estão características individuais (basicamente a educação, no caso) que mantêm relação direta com as probabilidades de pertencer ao grupo dos ricos. No segundo, estão desvantagens competitivas diretamente relacionadas à discriminação racial que, em termos operacionais, podem ser aferidas por um coeficiente que expresse a desvantagem dos negros com relação aos brancos, como pelas diferenças, entre os grupos raciais, no conjunto de coeficientes que associam as características individuais aos rendimentos. Em outras palavras, as desvantagens diretamente associadas à condição racial podem ser compreendidas tanto pela diferença entre probabilidades de riqueza aferida por um único coeficiente associado à condição de negro como, de modo mais complexo, pelas diferenças, entre negros e brancos, nas condições para que um mesmo nível de atributos individuais se converta em chance de pertencer ao grupo dos ricos. Finalmente, a terceira fonte de disparidade racial de riqueza encerra o conjunto residual de fatores não observados.

A primeira hipótese abordada neste capítulo é a de que a desigualdade dos níveis educacionais medeia apenas discretamente a disparidade racial de riqueza. Em outras palavras e de um ponto de vista prático, a correção das desigualdades 
educacionais teria um potencial apenas moderado para corrigir a desigualdade entre negros e brancos na composição do grupo dos ricos. Essa hipótese decorre do próprio fato de que a educação explica apenas moderadamente as chances de riqueza. A segunda hipótese é a de que as condições diferenciais para a conversão dos níveis educacionais em rendimentos têm um impacto muito mais saliente sobre a disparidade de riqueza do que sobre a desigualdade de rendimentos médios entre negros e brancos. Resultados de decomposição JMP utilizados no segundo capítulo mostram que metade da desigualdade de renda média entre negros e brancos é explicada por desigualdades educacionais, enquanto apenas 38\% da desigualdade de renda no $99^{\circ}$ quantil pode ser explicada dessa forma. Será investigado agora o cenário da desigualdade racial na composição do grupo dos ricos.

É importante notar que a situação da mulher negra tem chamado atenção de pesquisadores pela especificidade que a interseção entre os fatores raça e gênero lhe confere. As discussões ultrapassam o estudo da desigualdade social, desenvolvendo-se muito fortemente em áreas de pesquisa que procuram tematizar as relações entre cultura, política e poder que se estabelecem em torno da condição dessas mulheres (CARNEIRO, 2003; SEBASTIÃO, 2010). Nos estudos sobre desigualdade, mais especificamente, autores preocupados com processos de discriminação têm notado cada vez mais a necessidade de oferecer um tratamento específico à situação da mulher negra, invariavelmente associada a níveis críticos em indicadores de condição socioeconômica (SOARES, 2000; BIDERMAN; GUIMARÃES, 2004; DE CARVALHO; NÉRI; DO NASCIMENTO SILVA, 2006; MATOS; MACHADO, 2006; SOUZA, RIBEIRO; CARVALHAES, 2010). O presente trabalho não pretende ignorar esse fato, o que implica abordar conjuntamente as desigualdades condicionais à raça e ao gênero, mesmo que o foco, no presente caso, recaia especificamente sobre a desigualdade racial. A condição da mulher negra encerra uma faceta importante dessa desigualdade.

Do mesmo modo que ocorre com a desigualdade de renda em geral no que se refere à disparidade de riqueza, a condição de gênero diverge da condição racial 
no que tange à mediação por desigualdades educacionais. Enquanto a desvantagem dos negros é em parte mediada por desigualdades educacionais, a desvantagem das mulheres é tal que persiste nos maiores níveis de escolaridade da população feminina. Já quando se considera a situação da mulher negra, especificamente, observa-se um quadro mais complicado, já que, na população aqui em estudo, ela tem níveis educacionais inferiores aos de pessoas brancas e superiores apenas aos de homens negros, além de uma distribuição extremamente desvantajosa ao longo das áreas de formação superior. Assim, as mulheres negras não contam com o mesmo nível de vantagens, em termos educacionais, com que as mulheres brancas contam.

Em geral, a condição de negro está associada a menores rendimentos médios que a condição de mulher. Contudo, quando se desconta a mediação da desigualdade educacional, essa ordem se inverte, estando o sexo feminino associado a maiores desvantagens que a cor (BIDERMAN; GUIMARÃES, 2004). Dada a intensificação da desigualdade racial em níveis mais elevados de renda, espera-se que o mesmo não ocorra em se tratando da disparidade de riqueza. Além disso, espera-se que a mediação da disparidade de riqueza por áreas de formação no ensino superior difira segundo raça e gênero, uma vez que as barreiras às pessoas de cor parecem estar, antes de tudo, no acesso mesmo a esse nível de ensino. O menor nível de acesso das pessoas negras ao nível superior restringe, por si só, os impactos da distribuição não uniforme ao longo das áreas de formação sobre a disparidade de riqueza. Por outro lado, é possível que as desvantagens em termos de formação específica eclipsem as vantagens em níveis globais de educação que as mulheres negras possuem em relação ao homem negro, uma vez que seu maior acesso ao nível superior de ensino anda junto com uma alta concentração em áreas de formação pouco afluentes. Assim, a hipótese é a de que, para as mulheres negras, os níveis educacionais não cumpram um papel considerável a favor de suas probabilidades de riqueza nem mesmo em relação ao grupo dos homens negros, que são, em geral, menos educados.

Resta indagar como as outras duas fontes de disparidade de riqueza se comportam quando se considera simultaneamente a raça e o sexo. É provável que as 
condições diferenciais para a conversão da educação em oportunidades de riqueza prejudiquem primeiramente as mulheres e, depois, as pessoas negras em geral. Se as mulheres são mais escolarizadas, é de se esperar que sua sub-representação entre os ricos se deva em muito a dificuldades para converter seus níveis educacionais em chances de riqueza. Assim, pode haver uma vantagem dos homens negros em relação às mulheres brancas no que se refere a essas condições, enquanto os fatores não observados devem agir em desvantagem dos primeiros, eclipsando as vantagens em termos de condições. Em termos de fatores não observados, é de se esperar uma vantagem das mulheres brancas com relação aos homens negros. Isso porque esses fatores certamente incluem uma série de vantagens associadas à origem social, origem que desfavorece sistematicamente as pessoas negras, concentradas em estratos mais pobres, mas não as mulheres brancas, que se distribuem pelas famílias de todos os estratos socioeconômicos. Quanto à mulher negra, especificamente, espera-se que ela esteja em aguda desvantagem, tanto nas condições para a conversão da educação em chances de riqueza quanto em fatores não observados. Em resumo, espera-se que a mulher negra esteja em desvantagem em razão de todas as três fontes de disparidade de riqueza mencionadas anteriormente.

Finalmente, este capítulo também aborda a hipótese de que a disparidade racial de riqueza condicional às áreas de formação superior segue o padrão de acomodação das relações sociais em posições de classe, sendo maior para as áreas de formação mais afluentes. Em outras palavras, espera-se que, quanto maior for a probabilidade de riqueza associada a determinada área de formação, maior será a disparidade racial de riqueza condicional a essa área, em função do princípio subjacente que contraria a presença de negros em posições de status socioeconômico mais elevado. Se isso é verdade, a mediação da disparidade racial de riqueza pelas áreas de formação possui um caráter especialmente perverso. Ela operaria não apenas pela concentração de negros em áreas de formação menos afluentes, como também pela penalização mais severa dos negros que ingressam em áreas de formação mais fortemente associadas a altos rendimentos. 


\subsection{Os métodos utilizados}

Do ponto de vista operacional, a disparidade racial de riqueza pode ser abordada por meio da técnica de regressão logística, que permite que se estime a influência

de diversos fatores sobre a probabilidade de riqueza. Assim, operacionalmente, a questão se transforma em estimar a relação de um conjunto de variáveis explicativas sobre uma variável binária, que assume o valor de um quando uma pessoa pertence ao grupo dos $1 \%$ mais ricos e o valor de zero quando não pertence. É verdade que para esse tipo de propósito há, entre alguns pesquisadores, uma preferência pelo modelo probit. Essa preferência é justificada por certas vantagens técnicas, já que a regressão logística pressupõe algumas características na distribuição dos dados que, quando não satisfeitas, prejudicariam, em tese, a confiabilidade dos resultados obtidos. Contudo, Haan (2006) mostra que, na prática, não há prejuízos relevantes quanto à fidedignidade dos resultados de modelos logísticos quando comparados a modelos mais complexos e isentos desses pressupostos, isso mesmo quando esses pressupostos são seriamente violados pelas características da distribuição dos dados analisados. Sendo assim, nada parece justificar os custos de se lidar com modelos mais complexos, menos familiares e menos intuitivos.

Em várias ocasiões, se utilizará essa técnica em exercícios orientados pelas noções de controle e de efeitos parciais. A ideia é lançar um modelo básico para obter um coeficiente associado à variável explicativa (indicadores de raça e de sexo ou uma combinação dos dois), coeficiente que expressa a associação entre tal variável e a probabilidade de ser rico. Ao acrescentar o controle pelos níveis educacionais, espera-se que essa associação se altere, porque parte da relação entre raça e riqueza, assim como a relação entre gênero e riqueza, é mediada por desigualdades educacionais. Uma nova modificação é esperada quando se consideram as diferentes áreas de formação superior, pois as desigualdades raciais e de gênero na distribuição por essas áreas também medeiam a disparidade de riqueza. É importante ter em mente, contudo, que a interpretação dos coeficientes numa regressão logística não é tão 
direta e intuitiva quanto numa regressão linear. Embora a regressão logística estime probabilidades, essas probabilidades não são diretamente expressas pelos coeficientes associados às variáveis. Mais do que isso, as probabilidades estimadas pela regressão logística não são constantes ao longo da superfície de resposta do modelo (entenda-se por essa superfície o conjunto de todas as combinações possíveis entre os valores que as variáveis explicativas podem assumir), o que quer dizer que não é possível falar, por analogia à regressão linear, de um coeficiente que expresse os impactos da condição racial sobre a probabilidade de ser rico mantendo-se constantes as outras variáveis do modelo. Colocando de outro modo, a relação entre a variável raça e a probabilidade de ser rico depende dos valores das outras variáveis explicativas.

É diante desse fato que os pesquisadores geralmente trabalham com um resultado específico da regressão logística: a razão de chances que, diferentemente das probabilidades, é constante ao longo da superfície de resposta. Mas nem sempre isso resolve o problema. A razão de chances geralmente é interpretada como se fosse uma razão entre probabilidades. Por exemplo: uma razão de chances de 0,5 associada à variável raça indicaria que a probabilidade de negros serem ricos é metade da probabilidade de brancos o serem. No entanto, essa interpretação pode levar a equívocos consideráveis (HOETKER, 2007), já que a razão de chances não é, de fato, uma razão entre probabilidades, mas, antes, outra quantidade, pouco interpretável diretamente, mas que aproxima satisfatoriamente a razão de probabilidades, desde que as probabilidades em questão sejam pequenas (NORTON; WANG; AI, 2004). Felizmente, as probabilidades de se estar entre os ricos é pequena condicional a quase todas as combinações possíveis das variáveis explicativas consideradas aqui. Exceção para quando se trata de pessoas com formações específicas fortemente associadas à riqueza. Para essas, a probabilidade de ser rico é relativamente grande, ainda mais em se tratando de pessoas mais velhas. Sendo assim, em alguns exercícios será utilizada a razão de chances como aproximação de uma razão de probabilidades constante ao longo da superfície de resposta do modelo. Nessas ocasiões, será possível uma comparação direta com resultados de 
regressões lineares, já que a razão de chances tem interpretação direta e análoga à dos coeficientes obtidos por aquela outra técnica. Em outras ocasiões, contudo, serão utilizados comandos que permitem estimar probabilidades em diferentes pontos da superfície de resposta, e a razão de probabilidades será calculada diretamente a partir desses resultados, em vez de aproximada pela razão de chances. Como as razões de chance serão utilizadas apenas quando oferecerem uma boa aproximação da razão de probabilidades, os dois termos serão utilizados como equivalentes.

Será utilizada também a chamada decomposição de Oaxaca-Blinder, inicialmente desenvolvida para regressões lineares e, mais tarde, generalizada para modelos não lineares por Fairlie (1999) e por Bauer (2006). A técnica consiste num exercício contrafatual, no mesmo espírito da decomposição de Juhn-Murphy-Pierce já exposta em capítulos anteriores. Na verdade, trata-se de uma decomposição mais simples, que não trata da distribuição de resíduos e se atém à decomposição de diferenças entre médias. No presente contexto, essa decomposição parte da diferença entre as probabilidades que pessoas de dois grupos disjuntos têm, em média, de serem ricas. Por meio da decomposição, é possível, em tese, quantificar a porção dessa diferença que se deve à desigualdade educacional entre os grupos em questão. Na verdade, contudo, os resultados da decomposição de Oaxaca-Blinder podem variar bastante de acordo com determinadas escolhas operacionais. Essas escolhas são motivadas pela discussão introduzida por Cotton (1988) em torno do significado teórico desse tipo de exercício. Segundo o autor, a discriminação não opera apenas impondo uma desvantagem relativa ao grupo discriminado, mas também uma vantagem relativa ao grupo dominante. O argumento é que não se deveria assumir que a discriminação se relaciona à renda, à educação ou a qualquer outro indicador de condição socioeconômica apenas pela penalização do grupo dominado, mas também pela premiação do grupo dominante.

Essa reflexão instaurou um debate sobre como mensurar não apenas as desvantagens relativas aos negros (ou às mulheres, ou a qualquer que seja o grupo discriminado em questão) como também as vantagens relativas aos brancos. Os autores estão em 
acordo quanto à ideia de que, para tanto, seria necessário estimar o que seria a distribuição de renda não discriminatória (COTTON, 1988; OAXACA; RANSOM, 1994; YUN, 2009). Na prática, geralmente se espera que o conjunto de coeficientes representando a estrutura não discriminatória de distribuição de renda estaria em algum ponto entre o conjunto de coeficientes das duas distribuições realmente observadas. Assim, no caso da decomposição em um modelo logístico, a técnica passou por diferentes propostas de especificação no que se refere a como ponderar as médias (no caso, as probabilidades médias) dos grupos em comparação, de modo a obter uma expressão do que seria a estrutura não discriminatória de distribuição das probabilidades.

O problema é que essas diversas especificações oferecem, no presente caso, estimativas muito divergentes do que seriam as contribuições relativas das diferentes fontes de disparidade: características individuais e processos discriminatórios. Essa inconsistência da técnica ficou constatada em uma análise de sensibilidade das especificações de ponderação propostas por Oaxaca (1973), Oaxaca e Ransom (1994) e por Cotton (1988), cujos resultados são omitidos na presente exposição por brevidade e objetividade. Por outro lado, de acordo com os resultados da análise de sensibilidade, a técnica é consistente para detectar a variação relativa na contribuição das fontes de disparidade ao longo de diferentes estágios de especificação de um mesmo modelo. No caso, trata-se de uma especificação sem controle por educação, outra com controle por educação em geral e uma terceira com controle por formação específica. Sendo assim, a técnica de decomposição é utilizada para analisar a evolução da contribuição dos atributos individuais e da educação, mais especificamente, ao longo dessas três especificações de modelo.

Além desses exercícios, alguns cenários contrafatuais serão delineados, utilizando-se comandos básicos após a estimação de modelos. Nesse caso, a referência para os exercícios é o próprio manual do Stata/SE versão 11, na parte em que esse se refere ao comando “margins”. Por fim, utiliza-se também a decomposição de Juhn-Murphy-Pierce, já exposta no primeiro capítulo. Ao incluir o trato com a distribuição de resíduos, essa técnica será útil para uma identificação mais precisa do papel das condições para a 
conversão da educação em oportunidades de riqueza. Embora baseada em regressões lineares, essa técnica, diferentemente da decomposição Oaxaca-Blinder, permite que se construa distribuições contrafatuais inteiras, incluindo o grupo dos $1 \%$ mais ricos. Sendo assim, é possível analisar as mudanças na composição desse grupo em diferentes cenários contrafatuais, mesmo partindo de uma estimação centrada na média.

O agrupamento das áreas de formação é o mesmo já utilizado por Souza e Galvão (2014), e segue de perto a própria classificação de áreas de formação adotada pelo Censo, além de um procedimento ad hoc de agrupamento com base em regressões logísticas sucessivas. Segundo esse procedimento, formações que têm associações semelhantes com a probabilidade de ser rico são sucessivamente agrupadas, até que se obtenha um conjunto de categorias o mais parcimonioso possível. Como o comportamento que interessa ao presente estudo é a relação entre determinada formação e a riqueza, formações com níveis próximos de associação podem ser agrupadas sem trazer grandes prejuízos de informação, de modo que se chega a um conjunto mais econômico de categorias, o que facilita tanto a exposição quanto a análise. Finalmente, cabe salientar que serão utilizados também recursos gráficos, como diagramas de dispersão, muitas vezes a partir de resultados da implementação de modelos mais complexos. Esses recursos permitirão tanto a visualização de propriedades básicas da distribuição dos dados quanto o teste de determinadas hipóteses.

\subsection{A mediação educacional da disparidade racial de riqueza}

Dentre os ricos, mais de $74 \%$ das pessoas possuem ao menos curso superior completo, indicando uma forte prevalência de altos níveis de ensino. Por outro lado, das pessoas com curso superior completo, apenas cerca de $10 \%$ são ricas. Em outras palavras, há uma minoria de pessoas altamente escolarizadas que compõe uma porção majoritária dos ricos: os ricos altamente escolarizados. Não apenas a conclusão do nível superior de ensino como também as diferenças em termos de área de formação constituem um crivo importante na composição desse grupo de pessoas. 
Diante disso, espera-se que parte da disparidade racial de riqueza seja mediada pela desigualdade educacional entre negros e brancos, especialmente quando se consideram as diferenças em termos de área de formação no ensino superior. Isso porque as pessoas negras são menos frequentes em cursos associados a maiores rendimentos. Nesse sentido, cabe perguntar em que medida a disparidade racial de riqueza é mediada por desigualdades educacionais, o que também significa perguntar em que medida, tudo mais permanecendo constante, a eliminação da desigualdade educacional entre negros e brancos corrigiria a disparidade racial de riqueza.

Essa é uma questão relevante não apenas do ponto de vista teórico, mas também prático. Por um lado, dada a ciência de que a desigualdade socioeconômica entre negros e brancos é substancialmente mediada por desigualdades educacionais, no Brasil, têm-se recentemente amadurecido ações visando uma maior inserção de negros no nível superior de ensino. Por outro lado, mais recentemente, sancionou-se lei prevendo reserva de vagas para negros nas contratações no âmbito da administração pública federal, das fundações e empresas públicas, assim como das sociedades de economia mista controladas pela União. Nesse último caso, a motivação é a ideia de que parte substancial da desigualdade racial de renda não é mediada por desigualdades educacionais, fazendo-se necessário intervir diretamente no mercado de trabalho. Sendo o funcionalismo público um segmento com elevada renda média, onde se concentram algumas carreiras com altos rendimentos, é de se esperar que essa política funcione em alguma medida como um mecanismo de inserção de pessoas negras nos estratos mais ricos, ou seja, de correção da disparidade racial de riqueza. É importante, portanto, também do ponto de vista prático, investigar em que medida a disparidade racial de riqueza é mediada pela desigualdade educacional entre negros e brancos. À medida que ela o é, ações afirmativas no sistema de ensino ganham suporte. À medida que ela não o é, ganham suporte também propostas de ação afirmativa voltadas diretamente para o mercado de trabalho.

Para acessar empiricamente essa questão, utiliza-se a lógica dos efeitos parciais. A ideia é lançar um modelo básico para obter um coeficiente associado à variável 
raça, o qual expresse o quanto a condição de negro afeta a probabilidade de que alguém negro pertença ao grupo dos ricos. Ao acrescentar-se o controle pelos níveis educacionais, espera-se que essa associação se reduza, porque parte da relação entre raça e riqueza é explicada por diferenças educacionais entre negros e brancos. Essa redução deve ser ainda maior quando se consideram as diferentes áreas de formação, pois a escassez de negros nas formações de elite cumpre também um papel importante nessa mediação. Utilizam-se, assim, três especificações para o modelo de regressão logística. No primeiro, não há indicadores de nível educacional. No segundo, toma-se a educação superior como um bloco. No terceiro, a educação superior é desagregada em termos de áreas de formação. O controle pela segmentação regional e pela residência em zonas rurais ou urbanas foi implementado pela limitação da amostra às pessoas com residência urbana na região Sudeste. A variável idade foi incluída, mas não com um termo quadrático. Uma modelagem por meio de regressão linear da relação entre idade e renda aponta para o entorno dos 57 anos como o ponto de pico na variação da renda em função da idade. Esse número é bem próximo dos 60 anos, idade máxima incluída na amostra em estudo, com o que a especificação do padrão curvilíneo não acrescenta muito em informação. Considerando isso e, diante das dificuldades no trato adequado com termos quadráticos em regressões logísticas (NORTON et al., 2004), optou-se pela inclusão da variável idade simplesmente em termos de anos completos. Cada uma das três especificações foi aplicada em separado para homens e mulheres. A Tabela 5.1 apresenta os resultados:

O modelo mais básico inclui apenas as variáveis raça e idade. A razão de chances indica que, considerando zonas urbanas da região Sudeste, negros e negras têm algo em torno de $14 \%$ das probabilidades que pessoas brancas têm de estarem entre os mais ricos. Quando se inclui a educação em geral no modelo, a desvantagem das pessoas negras se reduz substancialmente. Os negros têm agora quase 34\% das probabilidades que os brancos têm de estarem entre os homens mais ricos. Entre as mulheres, essa mudança é menor, com a razão de probabilidades entre 
negras e brancas chegando a 29\%. Como esperado, a especificação dos indicadores educacionais por áreas de formação leva a uma redução ainda maior dos efeitos diretamente associados à raça. A razão de probabilidades passa a 36\% entre os homens e a $33 \%$ entre as mulheres.

Tabela 5.1: Razão de chances de riqueza com três níveis de controle para a educação. Brasil, Sudeste urbano, renda igual ou superior a um salário mínimo, 2010.

(continua)

\begin{tabular}{|c|c|c|c|c|c|c|}
\hline & \multicolumn{6}{|c|}{ Razão de chances } \\
\hline & \multicolumn{2}{|c|}{$\begin{array}{l}\text { Sem controle } \\
\text { por educação }\end{array}$} & \multicolumn{2}{|c|}{ Educação geral } & \multicolumn{2}{|c|}{ Educação específica } \\
\hline & Homens & Mulheres & Homens & Mulheres & Homens & Mulheres \\
\hline $\begin{array}{l}\text { Fundamental } \\
\text { completo }\end{array}$ & - & - & 1,989 & 1,435 & 1,991 & 1,471 \\
\hline Médio completo & - & - & 4,648 & 3,196 & 4,659 & 3,339 \\
\hline $\begin{array}{l}\text { Superior } \\
\text { completo }\end{array}$ & - & - & 37,518 & 21,652 & - & - \\
\hline Medicina & - & - & - & - & 129,030 & 130,424 \\
\hline Direito & - & - & - & - & 44,0924 & 59,691 \\
\hline $\begin{array}{l}\text { Administração, } \\
\text { Comércio e } \\
\text { Economia }\end{array}$ & - & - & - & - & 36,104 & 28,095 \\
\hline $\begin{array}{l}\text { Engenharia, } \\
\text { Produção, } \\
\text { Arquitetura }\end{array}$ & - & - & - & - & 51,030 & 54,233 \\
\hline $\begin{array}{l}\text { Serviços, } \\
\text { transporte, } \\
\text { proteção }\end{array}$ & - & - & - & - & 33,688 & 15,040 \\
\hline $\begin{array}{l}\text { Jornalismo e } \\
\text { informação }\end{array}$ & - & - & - & - & 29,459 & 32,121 \\
\hline $\begin{array}{l}\text { Agricultura } \\
\text { e pesca }\end{array}$ & - & - & - & - & 37,442 & 32,255 \\
\hline $\begin{array}{l}\text { Ciências } \\
\text { biológicas, } \\
\text { Física, } \\
\text { Matemática }\end{array}$ & - & - & - & - & 19,680 & 11,941 \\
\hline
\end{tabular}


Tabela 5.1: Razão de chances de riqueza com três níveis de controle para a educação. Brasil, Sudeste urbano, renda igual ou superior a um salário mínimo, 2010.

(conclusão)

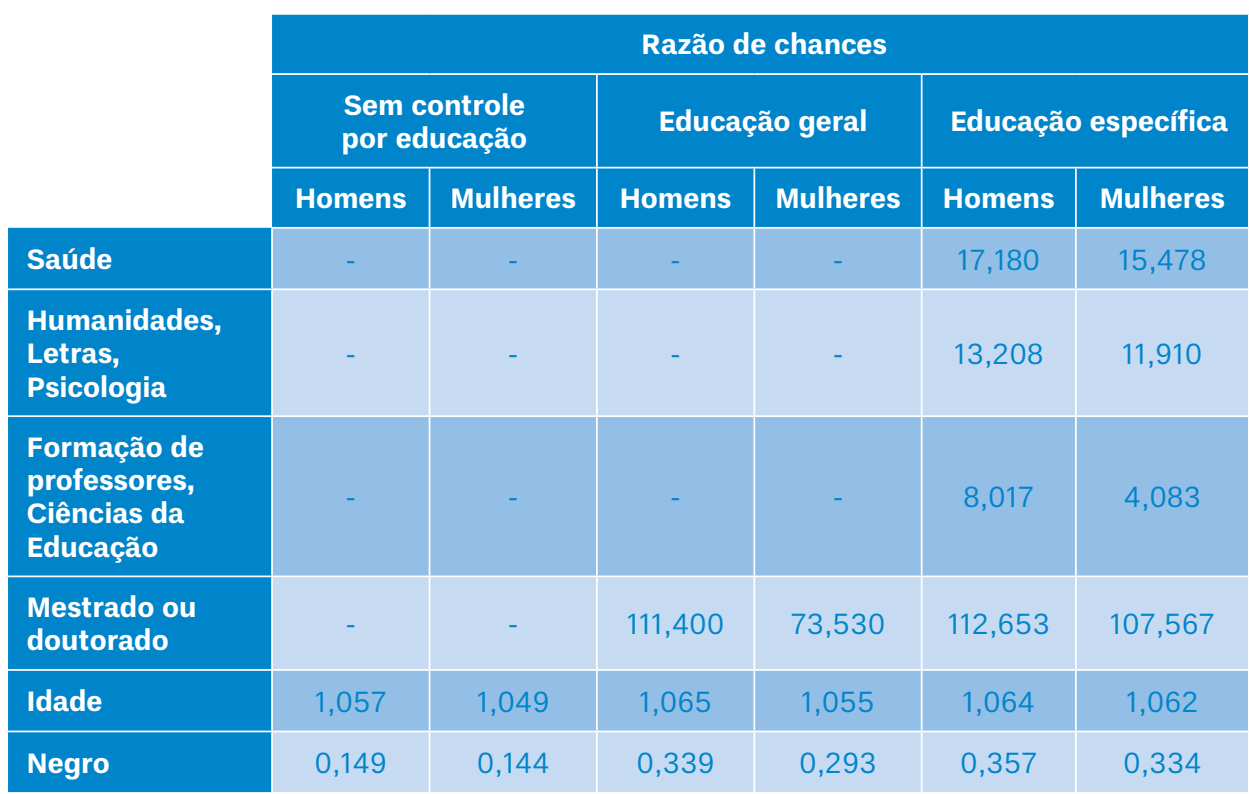

Fonte: IBGE - Censo Demográfico 2010 - Microdados. Elaboração própria.

Quanto à educação em si, pode-se ver, na segunda especificação do modelo, uma razão de chances da ordem de 37 associada ao nível superior de ensino. Como ainda é relativamente pequena a probabilidade de ser rico condicional à conclusão de nível superior (menos de 10\% das pessoas com esse nível de instrução são ricas), esse número pode ainda ser interpretado como indicação de que pessoas com curso superior completo são, grosso modo, 37 vezes mais prováveis de estarem entre os ricos do que pessoas sem esse nível educacional. Quando se considera a terceira especificação dos modelos, observa-se a grande heterogeneidade existente entre as áreas de formação no que se refere à relação com a riqueza. Previna-se, contudo, de interpretar todas as razões de chance como razões de probabilidade, já que, nesse caso, para alguns cursos, a probabilidade de ser rico é bastante alta. Assim, embora as razões de chance apontem para uma associação global muito forte entre 
a riqueza e as formações nas áreas da medicina, do direito, das engenharias, assim como a conclusão do doutorado, não é propriamente acertado dizer que, entre os homens, médicos têm uma probabilidade de serem ricos 129 vezes maior que os não médicos, mantidas constantes as outras variáveis do modelo. Nesse caso, a razão de chances não é uma boa aproximação da razão de probabilidades.

Esses resultados permitem avançar duas conclusões. A primeira delas é que a disparidade racial de riqueza é consideravelmente mediada pela desigualdade educacional entre negros e brancos, mas, embora substancial, essa mediação está longe de ser definitiva. Reduzir ou, virtualmente, eliminar a desigualdade educacional entre negros e brancos, mesmo incluindo aquela em termos de áreas de formação, reduziria a disparidade racial de riqueza, mas, nem de perto, a eliminaria. Em boa medida, isso se deve ao fato de que a educação explica apenas moderadamente a participação no grupo dos ricos. Igualdade educacional, portanto, mesmo em se tratando de uma igual distribuição dos grupos raciais pelas diferentes áreas de formação, não significaria iguais oportunidades de riqueza. Assim, a correção da desigualdade racial na educação constitui um mecanismo efetivo, mas não definitivo para a correção da disparidade racial de riqueza.

A segunda conclusão é a de que a contribuição da desigualdade por áreas de formação para a disparidade racial de riqueza é relativamente discreta. A segunda especificação do modelo mostra uma correção substancial quando se controla a desigualdade em termos de educação em geral. A terceira especificação, que considera as diferenças por áreas de formação, leva a uma correção adicional relativamente modesta. A contribuição da desigualdade educacional para a disparidade racial de riqueza parece estar mais relacionada ao baixo acesso de pessoas negras ao nível superior de ensino do que às diferenças por área de formação no interior desse nível.

\subsection{Condições para a conversão da educação em oportunidades de riqueza}

Se, por um lado, a educação medeia parte considerável da disparidade racial de riqueza, por outro lado, determinado nível educacional não se converte igualmente 
em oportunidades de riqueza para negros e brancos. Esse tipo de diferença é que está mais sujeita a refletir mecanismos de discriminação direta. Claro que outras interpretações concorrentes podem ser levantadas. A primeira delas seria sobre a qualidade de ensino. As credenciais de negros médicos e advogados, por exemplo, podem, em média, valer relativamente menos do que as mesmas credenciais de brancos, em razão desses últimos estarem concentrados nas instituições com maior qualidade ou prestígio. $\mathrm{O}$ acesso a redes de contatos também pode cumprir um papel importante na conversão de credenciais em riqueza. Esses contatos não apenas um tipo de recurso, amplamente denominado capital social como também criam condições mais ou menos favoráveis para a conversão das credenciais em status e riqueza. Por essa rede de contatos, circulam informações e fluxos de influência que certamente podem aumentar as chances de determinada credencial ser convertida em altos níveis de rendimento. Essas vantagens devem estar associadas à condição de branco, mediando assim parte da desigualdade racial associada à raça.

Não obstante, as barreiras impostas pela discriminação direta não são menos dignas de serem reconhecidas enquanto mecanismos subjacentes responsáveis pelas desigualdades observadas, entre os grupos raciais, na habilidade para converter os mesmos níveis educacionais em chances de estar entre os ricos, até porque a discriminação direta certamente interage e, em alguma medida, se materializa na forma de outros mecanismos. Por exemplo, a discriminação racial implica restrições na aceitação social do negro, o que, se não necessariamente impede, dificulta seu acesso a redes de relações economicamente úteis. Nesse sentido, o capital social, em vez de uma explicação concorrente, passa a constituir, na verdade, um modo pelo qual a discriminação racial afeta as chances de vida. De todo modo, uma vez que as informações disponíveis não permitem que se diferenciem as contribuições dos diferentes mecanismos em jogo e muito menos que se analise a sua imbricada relação, opta-se aqui por falar, de maneira abrangente, das condições para a conversão de atributos individuais, sobretudo a educação, em oportunidades de riqueza, as quais são afetadas, ainda que não exclusivamente, pela discriminação racial direta. 
Para averiguar o quanto essas condições determinam a disparidade racial na probabilidade de estar entre os ricos, recorre-se a uma bateria de exercícios contrafatuais. Os exercícios são feitos com base num modelo em que a probabilidade de ser rico é dada de acordo com a idade, com a formação educacional específica e com a condição racial. O modelo é aplicado às pessoas residentes em zonas urbanas da região Sudeste. Assim, os fatores de segmentação geográfica são controlados sem serem, contudo, incluídos no modelo, de modo que os resultados podem ser interpretados exclusivamente por referência aos atributos individuais. Os padrões apresentados não diferem substancialmente quando se consideram outras regiões ou zonas rurais. Mais uma vez, a aplicação é feita para mulheres e homens separadamente. O modelo inclui um termo de interação entre raça e níveis educacionais. Testes formais sobre a melhor aderência do modelo interativo à distribuição das probabilidades não confirmam um incremento estatisticamente significativo na capacidade explicativa. Segue-se, no entanto, a orientação de Treiman (2009) que, diante do caráter não rigorosamente decisivo desses testes para modelos logísticos, recomenda a opção de acordo com motivações interpretativas, caso existam razões para se acreditar na existência de um processo de interação. No presente caso, a motivação é o fato de que a disparidade racial de riqueza, medida pela razão de probabilidades de riqueza entre negros e brancos, varia muito entre os diferentes níveis de ensino e as diferentes áreas de formação.

O modelo de regressão assim aferido representa, para negros e para brancos, o padrão de associação entre educação, idade e probabilidade de estar entre os ricos. Esses padrões diferem de acordo com os grupos raciais, o que se expressa por um coeficiente que associa a condição do negro a uma redução nas probabilidades de riqueza. Os recursos contidos na versão 11 do Stata/SE para o tratamento após estimações permitem que se compute a probabilidade média ${ }^{1}$ de riqueza sob as hipóteses de: (i) todas

1 A regressão logística atribui uma probabilidade a cada observação, probabilidade que difere segundo os valores da respectiva observação nas variáveis independentes. A probabilidade média é simplesmente a média das probabilidades atribuídas a cada observação, como seria o caso para qualquer outra grandeza contínua. A média de probabilidade de riqueza para os negros, por exemplo, é a 
as observações na amostra serem tratadas como pessoas brancas; (ii) todas serem tratadas como negras; (iii) apenas brancos serem tratados como brancos; (iv) apenas negros serem tratados como negros; (v) apenas negros serem tratados como brancos; e (vi) apenas brancos serem tratados como negros. $\mathrm{O}$ "tratar como” significa aplicar às observações em questão um valor determinado para a variável que define a condição que se lhes quer imputar. Por exemplo, tratar negros como brancos significa tomar todas as observações de pessoas negras, imputar a elas o valor que indica a condição de branco - no caso, atribuir o valor zero, em vez de um, à variável que indica a condição de negro - e então estimar a probabilidade resultante de acordo com o modelo estimado, utilizando, para todas as outras variáveis consideradas, os seus valores reais. No presente contexto, isso equivale a retirar, de todas as pessoas negras, as desvantagens associadas à condição racial e à sua interação com os níveis educacionais e, então, calcular a probabilidade média dessas pessoas serem ricas, considerando seus níveis reais de educação e de idade. A Tabela 5.2, a seguir, mostra os resultados dessa decomposição.

Tabela 5.2: Decomposição das probabilidades de riqueza. Brasil, Sudeste urbano, renda igual ou superior a um salário mínimo, 2010.

(continua)

\begin{tabular}{|l|c|c|c|c|c|}
\hline \multicolumn{1}{|c|}{ Homens } & \multicolumn{2}{c|}{ Mulheres } \\
\hline & $\begin{array}{c}\text { Probabilidade } \\
\text { de riqueza }\end{array}$ & $\begin{array}{c}\text { Razão de } \\
\text { probabilidades }\end{array}$ & $\begin{array}{c}\text { Probabilidade } \\
\text { de riqueza }\end{array}$ & $\begin{array}{c}\text { Razão de } \\
\text { probabilidades }\end{array}$ \\
\hline Global & $2,5 \%$ & Global & $1,1 \%$ & $42 \%$ \\
\hline $\begin{array}{l}\text { Todos como } \\
\text { brancos }\end{array}$ & 0,027 & $39 \%$ & $\begin{array}{c}\text { Todas como } \\
\text { brancas }\end{array}$ & 0,013 & \\
\hline $\begin{array}{l}\text { Brancos } \\
\text { como } \\
\text { brancos }\end{array}$ & 0,039 & $\begin{array}{c}\text { Brancas } \\
\text { como } \\
\text { brancas }\end{array}$ & 0,017 & \\
\hline $\begin{array}{l}\text { Negros } \\
\text { como } \\
\text { brancos }\end{array}$ & 0,015 & $\begin{array}{c}\text { Negras } \\
\text { como } \\
\text { brancas }\end{array}$ & 0,007 & \\
\hline
\end{tabular}

média entre as diferentes probabilidades que cada um dos negros, com seus diferentes graus de escolaridade e com suas desvantagens em relação aos brancos, tem de estar entre os ricos. 
Tabela 5.2: Decomposição das probabilidades de riqueza. Brasil, Sudeste urbano, renda igual ou superior a um salário mínimo, 2010.

\begin{tabular}{l|c|c|c|c|c|}
\hline \multicolumn{3}{|c|}{ Homens } & \multicolumn{3}{c|}{ Mulheres } \\
\hline & $\begin{array}{c}\text { Probabilidade } \\
\text { de riqueza }\end{array}$ & $\begin{array}{c}\text { Razão de } \\
\text { probabilidades }\end{array}$ & & $\begin{array}{c}\text { Probabilidade } \\
\text { de riqueza }\end{array}$ & $\begin{array}{c}\text { Razão de } \\
\text { probabilidades }\end{array}$ \\
\hline $\begin{array}{l}\text { Todos como } \\
\text { negros }\end{array}$ & 0,011 & $33 \%$ & $\begin{array}{c}\text { Todas como } \\
\text { negras }\end{array}$ & 0,005 & $33 \%$ \\
\hline $\begin{array}{l}\text { Brancos } \\
\text { como } \\
\text { negros }\end{array}$ & 0,017 & $\begin{array}{c}\text { Brancas } \\
\text { como } \\
\text { negras }\end{array}$ & 0,007 & \\
\hline $\begin{array}{l}\text { Negros } \\
\text { como } \\
\text { negros }\end{array}$ & 0,006 & $\begin{array}{c}\text { Negras } \\
\text { como } \\
\text { negras }\end{array}$ & 0,002 & \\
\hline $\begin{array}{l}\text { Brancos } \\
\text { como } \\
\text { brancos } \\
\text { e negros } \\
\text { como } \\
\text { negros }\end{array}$ & & $15 \%$ & & & \\
\hline
\end{tabular}

Fonte: IBGE - Censo Demográfico 2010 - Microdados. Elaboração própria.

Primeiramente, note-se que a probabilidade global de riqueza para os homens é de aproximadamente 2,5\%, enquanto para as mulheres esse valor é de 1,1\%. Essa probabilidade expressa simplesmente a proporção dos homens que são ricos e a de mulheres que são ricas, respectivamente. Os valores superam 1\% porque a residência em áreas urbanas no Sudeste, que define a subpopulação em questão, está positivamente associada à riqueza. Inspecionando os valores, nota-se que os homens negros teriam 2,6 vezes mais chances de serem ricos caso fossem tratados como brancos. Fossem as mulheres negras tratadas como brancas, sua probabilidade de riqueza seria três vezes maior. A probabilidade de homens brancos serem ricos é aproximadamente 2,2 vezes maior do que seria caso eles fossem tratados como negros. Para as mulheres brancas o valor equivalente é 2,3. Finalmente, homens brancos tratados como homens brancos e mulheres brancas tratadas como mulheres brancas têm probabilidade de riqueza quase sete vezes maior do que pessoas negras tratadas enquanto tais. Esse quadro indica que 
as condições gerais para a conversão de educação em oportunidades de riqueza têm um impacto considerável sobre a disparidade racial na composição do grupo dos ricos.

Quando se considera negros tratados como negros e brancos tratados como brancos, nota-se que os negros têm apenas 15\% das chances que os brancos têm de serem ricos. Entre as mulheres, o valor é quase o mesmo: 14\%. Tais valores representam a situação fática e equivalem basicamente às razões de chance expostas na Tabela 4.1 para o modelo não ajustado por níveis educacionais. Já quando se trata todos como os negros são atualmente tratados, a razão de probabilidades vai a 33\% tanto para os homens quanto para as mulheres. Quando se considera o cenário contrafatual em que todos são tratados como brancos, essa razão vai a 39\% entre os homens e a 42\% entre as mulheres. É notável que, em ambos os casos, a redução se equipara àquela que aconteceria sob a condição de igualdade educacional entre negros e brancos, expressa no último modelo exposto na Tabela 4.1, que considera as formações específicas. Lá, o ajuste pelas desigualdades educacionais entre negros e brancos traz as razões de probabilidade para 35\% entre os homens e para 33\% entre as mulheres. Assim, os resultados dessa decomposição indicam que o impacto das diferenças nas condições gerais para a conversão da educação em oportunidades de riqueza é equivalente ou ainda maior que o impacto da própria desigualdade educacional entre negros e brancos.

O exercício apresentado na Tabela 5.2 não permite, contudo, que se diferencie a contribuição de fatores não observados da contribuição da desigualdade nas condições para a conversão da educação em oportunidades de riqueza. Estritamente falando, as desigualdades nessas condições devem ser avaliadas com base em diferenças observadas, entre os grupos raciais, na relação entre os atributos individuais e as chances de se estar entre os ricos. A decomposição JMP, utilizada já no primeiro capítulo, pode ser mais uma vez utilizada aqui, com o objetivo de fazer essa distinção.

Para conduzir a decomposição, especifica-se uma regressão linear explicando a variação dos logaritmos dos rendimentos em função da idade e dos níveis educacionais, incluindo as formações específicas. Essa regressão é aplicada para negros e para brancos residentes em zonas urbanas da região Sudeste, em separado. Com base 
nessas duas regressões, é possível simular qual seria a distribuição de renda caso todos os fatores não observados que a afetam tivessem, para os negros, a mesma distribuição que têm para os brancos. Num segundo passo, é possível estimar qual seria a distribuição de renda se, além da mesma distribuição de resíduos, os negros tivessem também os mesmos coeficientes que os brancos, ou seja, a mesma estrutura de distribuição de renda em função dos atributos individuais incluídos no modelo. Em cada uma dessas situações hipotéticas, identifica-se qual seria a proporção de negros no grupo dos ricos. Como essa técnica de decomposição também é sensível à escolha do grupo de referência para as simulações, cada fase do exercício é repetida atribuindo-se aos brancos as condições enfrentadas pelos negros.

A expectativa é, obviamente, que nas distribuições contrafatuais exista menor disparidade racial de riqueza. Numa delas se identifica como o cenário seria afetado pela equiparação dos grupos raciais no que se refere a fatores não observados. Na outra se identifica a contribuição dos coeficientes, ou seja, da desigualdade racial no que se refere ao modo como determinados níveis educacional e de experiência de vida se convertem em maiores rendimentos e, por conseguinte, em maior representação no grupo dos ricos. O exercício com essa decomposição permite, portanto, uma observação mais precisa da relevância das condições para a conversão de educação em chances de riqueza, expressa especificamente pela contribuição dos coeficientes. Já a contribuição dos fatores não observados expressa o impacto, para a disparidade racial de riqueza, de mecanismos subjacentes geradores de desigualdade racial que não a desigualdade em níveis educacionais. Os resultados da decomposição são mostrados na Tabela 5.3, a seguir. Para simplificar a exposição, mulheres e homens são considerados conjuntamente nesse exercício.

Os resultados mostram que tanto os fatores não observados quanto os coeficientes afetam substancialmente a disparidade racial de riqueza. A alteração das proporções em cada cenário contrafatual se deve tanto ao aumento do número de negros quanto à diminuição do número de brancos entre os ricos. Quando se atribui aos negros as condições realmente enfrentadas pelas pessoas brancas, o que acontece 
é o seguinte: como a distribuição de renda dos negros tem seu nível elevado pelos exercícios de simulação, uma quantidade de negros que estava abaixo da linha de riqueza passa a estar acima dela. Por outro lado, como a aumento no nível da renda dos negros altera a distribuição dos rendimentos como um todo, a linha de riqueza se eleva com as simulações e, permanecendo inalterada a distribuição de renda dos brancos, essa elevação implica diretamente a exclusão de um número deles do grupo dos ricos. Já quando se atribui aos brancos as condições enfrentadas pelos negros, o que acontece é um rebaixamento dos seus níveis de rendimento. Com isso, mais uma vez, brancos que eram ricos deixam de sê-lo. Por outro lado, como a linha de riqueza se reduz e a distribuição de renda das pessoas negras permanece inalterada, um número delas passa a estar incluído no grupo dos ricos.

Tabela 5.3: Simulação JMP para a participação no grupo dos ricos entre negros e brancos. Brasil, Sudeste urbano, renda igual ou superior a um salário mínimo, 2010.

\begin{tabular}{|l|c|c|c|c|}
\hline & \multicolumn{2}{|c|}{$\begin{array}{c}\text { Atribuindo aos negros a } \\
\text { condição dos brancos }\end{array}$} & $\begin{array}{c}\text { Atribuindo aos brancos a } \\
\text { condição dos negros }\end{array}$ \\
\hline & $\begin{array}{c}\text { Proporção } \\
\text { de brancos } \\
\text { entre os ricos }\end{array}$ & $\begin{array}{c}\text { Proporção de } \\
\text { negros entre } \\
\text { os ricos }\end{array}$ & $\begin{array}{c}\text { Proporção } \\
\text { de brancos } \\
\text { entre os ricos }\end{array}$ & $\begin{array}{c}\text { Proporção de } \\
\text { negros entre } \\
\text { os ricos }\end{array}$ \\
\hline $\begin{array}{l}\text { Distribuição real } \\
\text { Atribuindo } \\
\text { fatores não } \\
\text { observados }\end{array}$ & $83,9 \%$ & $16,1 \%$ & $16,1 \%$ \\
\hline $\begin{array}{l}\text { Atribuindo } \\
\text { fatores não } \\
\text { observados } \\
\text { e também os } \\
\text { coeficientes }\end{array}$ & $76,5 \%$ & $23,5 \%$ & $72,9 \%$ & $27,1 \%$ \\
\hline
\end{tabular}

Fonte: IBGE - Censo Demográfico 2010 - Microdados. Elaboração própria.

Considere-se primeiramente a situação em que se atribui aos negros as condições dos brancos. Observe-se a contribuição dos resíduos, que expressa o impacto de fatores não observados que afetam a distribuição de renda e, por conseguinte, 
as oportunidades de participação no grupo dos ricos. Atribuindo-se aos negros as mesmas condições dos brancos no que diz respeito a tais fatores, observa-se uma redução considerável na disparidade racial de riqueza, com a proporção de negros subindo de $16 \%$ para 23,5\%. Agora, o que aconteceria se os coeficientes relacionando educação, idade e riqueza entre os negros fossem exatamente os mesmos entre os brancos?² Nessa circunstância hipotética, a proporção de negros entre os ricos sobe a 34,5\%. Assim, se com a equalização dos fatores não observados o aumento na participação dos negros no grupo dos ricos seria de 7,5 pontos percentuais, com a situação hipotética de equalização dos coeficientes haveria um aumento adicional de $11 \%$. Assim, do efeito total exercido pelas simulações, que é de 18,5 pontos percentuais, $61 \%$ se devem aos coeficientes, ou seja, à medida mais precisa das condições diferenciais para a conversão dos atributos individuais em oportunidades de riqueza. Os 39\% restantes se devem aos fatores não observados.

Quando se faz a simulação pela atribuição aos brancos das condições enfrentadas pelos negros, a figura é um pouco diferente. Nessa situação, a equiparação da distribuição dos resíduos leva a proporção de negros entre os ricos de 16\% para 27\%. Quando se imputa aos brancos também os coeficientes que regem a distribuição de renda dos negros em função da educação e da idade, a proporção de negros entre os ricos chega a 33\%. As duas rodadas de simulação exercem, dessa vez, uma diferença total de 17 pontos percentuais, e não de 18,5 como no exercício anterior. Além disso, nesse caso, $65 \%$ dessa diferença total se deve aos fatores não observados e apenas

2 Note-se que, na verdade, o modelo considera tanto a educação quanto a idade. Trata-se, então, não apenas da educação formal mas também de como a experiência, ou, em sentido mais amplo, o aprendizado acumulado ao longo do curso de vida se relacionam aos níveis de rendimento individual. Contudo, como na população em estudo as diferenças raciais em termos de níveis de idade são muito discretas, pode-se interpretar os resultados por referência exclusiva à desigualdade educacional. Isso quando se considera o impacto da desigualdade entre os grupos raciais no que se refere ao nível dessas variáveis. Já no que se refere aos coeficientes, a associação entre idade e renda difere sensivelmente entre negros e brancos, os últimos aferindo maior vantagem para um mesmo aumento na idade. Diante disso, as diferenças que se devem ao comportamento dos coeficientes expressam mais precisamente a extensão das condições diferenciais para a conversão da educação e também do aprendizado ao longo do curso de vida, em oportunidades de riqueza. 
35\% aos coeficientes. Como se nota, há, basicamente, uma inversão entre as estimativas para as contribuições relativas dos resíduos e dos coeficientes. Além disso, como já notado, a alteração total exercida pelas simulações não é a mesma nos dois exercícios, sendo a diferença de 18,5 pontos percentuais num caso e de 17 no outro.

Essa diferença está relacionada ao fato de que a imputação das condições dos brancos à distribuição de renda dos negros expande essa distribuição enquanto a imputação das condições dos negros aos brancos exerce uma contração sobre a distribuição de renda desses últimos. Ocorre que a expansão na distribuição de renda dos negros na primeira situação altera mais a composição do grupo dos ricos. Também tem explicação o fato de que a atribuição das condições dos negros aos brancos resulta numa contribuição maior por parte dos fatores não observados. A verdade é que a distribuição de renda dos negros se comporta de modo menos sistemático, no sentido de ser explicada pelos fatores considerados nos modelos de regressão. Entre os brancos, a proporção da variância dos logaritmos dos rendimentos que é explicada pelas variáveis inseridas no modelo de regressão é de $42 \%$. Entre os negros, a mesma proporção é de 31\%. Isso quer dizer que os resíduos respondem por uma porção muito maior da distribuição de renda das pessoas negras e, consequentemente, quando sua distribuição é imputada às pessoas brancas, eles acabam exercendo um impacto muito considerável sobre a distribuição de renda dessas últimas. O mesmo fato sugere que se dê preferência ao exercício que se baseia na atribuição das condições dos brancos às pessoas negras, pois se trata da imputação das propriedades de um modelo com melhor performance.

Em síntese, os resultados da decomposição com regressão logística apontam para uma relevância crucial das desvantagens diretamente associadas à condição racial. No caso daqueles modelos de regressão, simula-se o que aconteceria com as probabilidades de riqueza caso: (i) retire-se dos negros todas as desvantagens associadas diretamente ao fato de serem negros ou (ii) se impute aos brancos essas desvantagens. O que se notou nessas circunstâncias foi uma correção na razão de probabilidades. De algo em torno de $14 \%$, esta passa à casa dos $30 \%$ quando se 
atribui aos brancos as mesmas desvantagens dos negros. A mesma razão chega ao entorno dos $40 \%$ quando se retira dos negros as suas desvantagens. Por outro lado, em exercícios anteriores expostos na Tabela 4.1, observou-se que o controle pelas desigualdades educacionais num modelo logístico, incluindo as diferenças por área de formação superior, traz a razão de chances dos 14\% para a casa dos $30 \%$. Mais precisamente, $35 \%$ entre os homens e $33 \%$ entre as mulheres. O que se conclui desses resultados é que a eliminação das desvantagens diretamente associadas à condição racial teria um impacto equiparável ao da própria eliminação das desigualdades educacionais, ou mesmo maior. Já com a decomposição JMP, pôde-se diferenciar a contribuição dos coeficientes da contribuição dos fatores não observados. Nesse caso, os exercícios não são absolutamente conclusivos a respeito de qual dessas fontes de disparidade de riqueza é a mais importante, havendo, contudo, razão para se dar mais fé ao exercício que aponta para a maior relevância dos coeficientes, que são a expressão mais adequada das desvantagens dos negros em termos de condições para converter seus atributos individuais em oportunidades de estar no grupo dos $1 \%$ mais ricos.

\subsection{A mediação educacional da disparidade de riqueza para as mulheres negras}

Condição racial e de gênero são dois fatores adscritos associados à disparidade de riqueza. Contudo, o papel da desigualdade educacional enquanto mecanismo mediador dessa disparidade difere substantivamente quando se trata de um ou de outro. As mulheres vêm ultrapassando consistentemente os homens em termos de níveis educacionais, enquanto a população negra mantém consistentemente níveis educacionais inferiores aos da população branca. Quando se estuda a desigualdade de renda em torno na média, o que se observa, em geral, é a massiva mediação da desigualdade racial de renda por desigualdades educacionais entre negros e brancos. Já entre as mulheres, o que existe é uma desigualdade de renda que persiste, mesmo 
sendo as mulheres, em média, mais educadas. A consequência disso é que, embora a desigualdade de renda em razão da cor seja maior que aquela em razão do sexo das pessoas, a equalização, via controles estatísticos, dos níveis educacionais em termos de raça e de gênero inverte o cenário. Fossem os negros tão educados quanto os brancos e os homens tão educados quanto as mulheres, a desigualdade de renda em razão da cor seria menor que a desigualdade de renda em razão do sexo, tudo mais mantido constante. Será que o mesmo vale em se tratando da disparidade de riqueza?

Para responder a essa questão, é possível implementar modelos de regressão linear para a desigualdade de renda em torno da média e de regressão logística para as probabilidades de riqueza. No primeiro caso, obtém-se a renda esperada de pessoas negras em termos de percentagem da renda esperada das pessoas brancas assim como a renda esperada de mulheres em termos de percentagem da renda esperada dos homens, mantidos constantes outros fatores. No caso da regressão logística, obtém-se a razão de probabilidades - aproximada pela razão de chances - de riqueza de pessoas negras em relação a pessoas brancas e de mulheres em relação aos homens, também mantidos constantes outros fatores. Ambos os modelos são implementados em dois estágios. O primeiro incluindo apenas a idade e os indicadores de condição racial e de gênero. O segundo incluindo também os níveis educacionais, considerando as diferentes áreas de formação superior. Os resultados são apresentados no Gráfico 5.1, a seguir.

As primeiras quatro barras se referem aos resultados de regressão linear e as quatro últimas aos resultados de regressão logística. As barras pretas representam os resultados da especificação sem controle por níveis educacionais. As barras cinzas representam os resultados da especificação com controle para esses níveis. Como se observa, a desigualdade de renda em torno da média se comporta da maneira esperada. A desigualdade bruta de renda em razão da raça é maior que aquela em razão do sexo. Contudo, quando se leva em conta a mediação educacional da desigualdade de renda, o cenário se inverte. A desigualdade diretamente associada à condição racial passa a ser menor que aquela diretamente associada 
à condição de mulher, o que acontece por dois motivos. Primeiramente, a renda esperada dos negros se eleva, uma vez que se descontam as desvantagens mediadas por seus menores níveis educacionais. Segundo, a renda esperada das mulheres é sensivelmente reduzida na medida em que se desconta sua vantagem educacional em relação aos homens.

Gráfico 5.1: Razão entre rendas médias e razão de chances de riqueza para homens e mulheres. Brasil, renda igual ou superior a um salário mínimo, 2010.

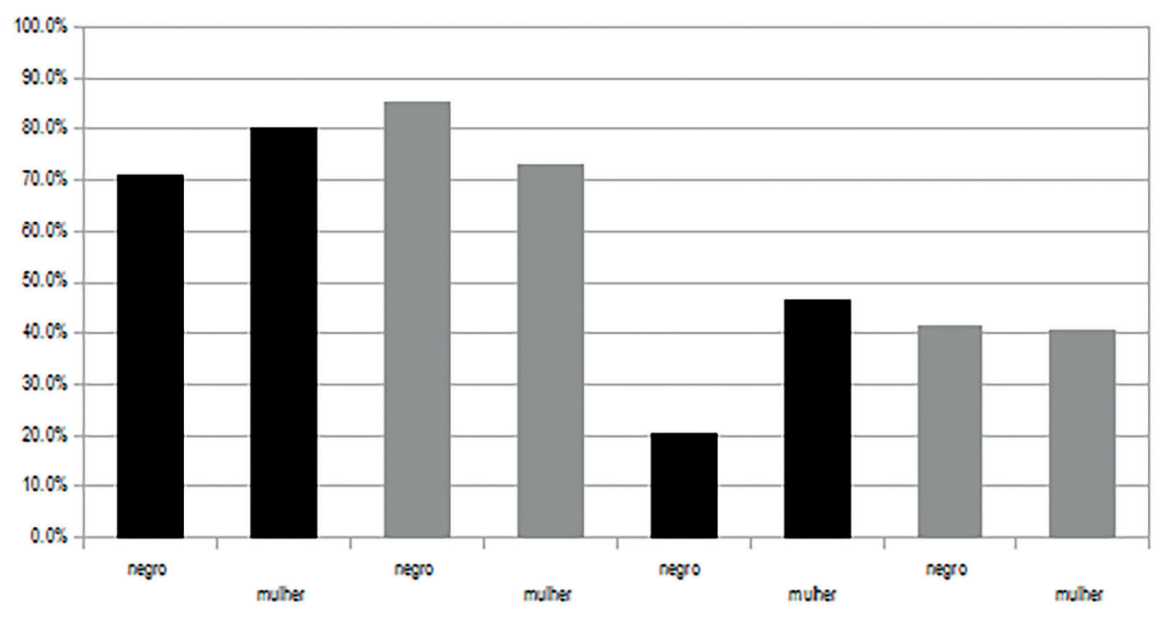

Fonte: IBGE - Censo Demográfico 2010 - Microdados. Elaboração própria.

Já quando se trata das probabilidades de riqueza, a situação é algo diferente. Primeiramente, nota-se que, em termos brutos, comparada ao que acontece no caso de rendas médias, a disparidade racial de riqueza supera a disparidade por gênero de maneira mais acentuada. No caso das diferenças brutas em renda média, a renda esperada de pessoas negras é $71 \%$ da renda esperada dos brancos. Para as mulheres, em comparação com os homens, esse valor é de $81 \%$. Por outro lado, em se tratando de disparidade de riqueza, negros são apenas 22\% tão prováveis quanto pessoas brancas de estarem entre os mais ricos, enquanto as mulheres são 47\% tão prováveis quanto os homens. Mais importante ainda, a inversão ocorrida com o desconto da mediação educacional não é tão acentuada no caso da disparidade de riqueza. O que há é muito mais uma equiparação, com a razão de probabilidades indo a 42\% entre 
negros e brancos e a $41 \%$ entre mulheres e homens. A resposta à questão é, portanto, negativa. Embora o comportamento da mediação educacional da disparidade de riqueza por sexo e raça seja, por um lado, semelhante ao da mediação educacional da desigualdade entre rendas médias, com a desvantagem dos negros sendo reduzida e a das mulheres aumentada pelo desconto dessa mediação, não há, contudo, no caso da disparidade de riqueza, uma nítida inversão na ordem desses fatores.

A relação entre raça, gênero e riqueza, portanto, é algo diferente da relação entre raça, gênero e renda média. Para avançar na compreensão da condição da mulher negra propriamente dita, é importante levar em conta a interação entre gênero e raça. Isso poderia ser feito pela inclusão de um termo de interação entre sexo e raça nos modelos considerados. Contudo, embora esse procedimento seja viável para os modelos de regressão linear, a inclusão desse termo nos modelos logísticos traria alguns problemas. O cômputo das desvantagens passaria a envolver cálculos sensivelmente mais complexos. Se no caso da regressão linear essa complexidade seria facilmente tratável, já no caso da regressão logística seria necessário utilizar comandos mais específicos para o cômputo de probabilidades. O maior problema nisso é que esse procedimento obrigaria a abandonar as razões de chance enquanto aproximação para uma razão de probabilidades praticamente constante ao longo da superfície de resposta do modelo. Seria necessário especificar probabilidades para diferentes posições nessa superfície, o que comprometeria fatalmente o exercício agora proposto, que se baseia numa comparação direta entre os resultados de regressões lineares e os de regressões logísticas. Enquanto na regressão linear ainda seria possível falar dos impactos de sexo e raça, mantidos constantes os níveis educacionais, o mesmo deixaria de ser possível com a regressão logística.

Sendo assim, opta-se por trabalhar com quatro categorias geradas pela combinação de sexo e raça: homens brancos, mulheres brancas, homens negros e mulheres negras. Essas categorias são disjuntas e, portanto, podem ser inseridas tanto na regressão linear quanto na regressão logística enquanto uma variável categórica. Assim, repete-se o exercício anterior utilizando os homens brancos como referência 
e aferindo-se as desvantagens dos outros três grupos com relação a eles. Como a probabilidade de ser rico condicional a qualquer uma dessas categorias é pequena para qualquer uma delas, apenas um pequeno número se encontra entre os ricos -, continua sendo possível interpretar a razão de chances como uma aproximação da razão de probabilidades de riqueza, praticamente constante ao longo da superfície de resposta. Os resultados são apresentados no Gráfico 5.2. As primeiras seis barras se referem aos resultados de regressão linear e as seis últimas aos resultados de regressão logística.

Gráfico 5.2: Razão entre rendas médias e razão de chances de riqueza para categorias de raça e gênero. Brasil, renda igual ou superior a um salário mínimo, 2010.

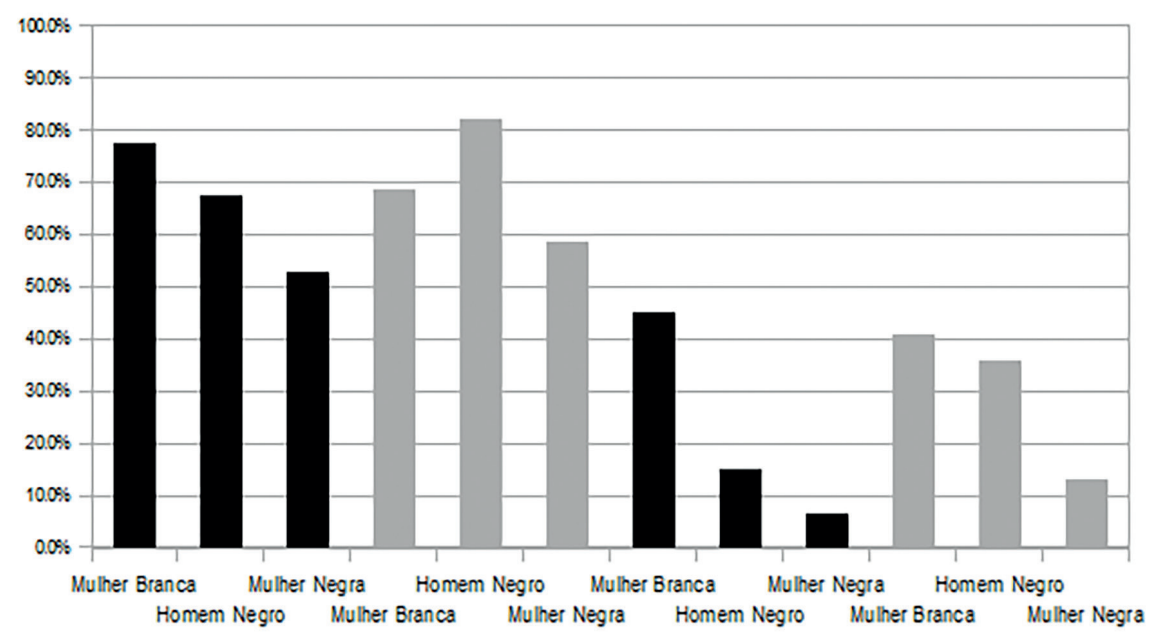

Fonte: IBGE - Censo Demográfico 2010 - Microdados. Elaboração própria.

O que se observa agora é um cenário muito mais informativo. No que se refere à desigualdade de renda em torno da média, observa-se o padrão esperado de inversão entre homens negros e mulheres brancas. Quando se desconta a mediação educacional, os primeiros passam a ter renda esperada mais próxima à dos homens brancos. A mesma inversão não ocorre, contudo, entre mulheres negras e mulheres brancas. Note-se que apenas a renda esperada das mulheres brancas, em termos de proporção da renda esperada dos homens brancos, sofre queda quando se desconta 
a mediação educacional, o mesmo não acontecendo com as mulheres negras que assistem, ao contrário, a um incremento em sua renda esperada. Isso indica que, para essas últimas, de maneira semelhante ao que ocorre com os homens negros, a desvantagem de renda em relação aos homens brancos é em parte mediada por desvantagens educacionais. Contudo, uma desvantagem muito maior persiste para elas após o desconto dessas desvantagens. Enquanto os homens negros se aproximam bastante dos homens brancos, saindo de 68\% para 82\% da renda esperada desses últimos, as mulheres negras sobem apenas para 58\%.

A distinção mais nítida, contudo, aparece quando se observa o que acontece com a mediação educacional da disparidade de riqueza. Nesse caso, não há em definitivo a inversão que existe no que se refere à desigualdade de renda em torno da média. O que há é uma modificação na topografia da disparidade. O desconto da mediação educacional aproxima os homens negros das mulheres brancas, mas mantém as últimas em melhores condições que os primeiros. Na verdade, mantém-se uma distância considerável entre eles: mulheres brancas ficam 41\% tão prováveis quanto os homens brancos de estarem entre os ricos, com a mesma distância sendo de 36\% para os homens negros. Por outro lado, a distância entre homens negros e mulheres negras se agrava, sobretudo porque o desconto da mediação educacional aumenta apenas discretamente as probabilidades de riqueza dessas últimas, enquanto para os homens negros esse aumento é bastante expressivo. Em termos brutos, homens e mulheres negros estão próximos, ambos em ampla desvantagem com relação às mulheres brancas e, mais ainda, aos homens brancos. Já quando se desconta a mediação educacional, as mulheres negras aparecem isoladas em último lugar.

O que se conclui é que a diferenciação por sexo e raça na mediação educacional da disparidade de riqueza comporta-se de modo bastante distinto daquilo que ocorre em se tratando de rendas médias. Enquanto para a renda média o desconto da mediação educacional leva a um cenário de maior saliência das desigualdades diretamente associadas ao sexo, no caso da disparidade de riqueza esse desconto não altera o cenário de maior saliência das desvantagens diretamente associadas 
à raça. No primeiro caso, o ordenamento resultante do controle por desigualdades educacionais se altera, colocando homens negros à frente de mulheres brancas, mas deixando mulheres negras atrás dessas últimas. O que se observa, portanto, é um ordenamento por gênero com um ordenamento secundário por raça. Em se tratando da disparidade de riqueza, mesmo com o desconto da mediação educacional, mantém-se um ordenamento racial primário com um ordenamento secundário por gênero. Pessoas brancas têm maior probabilidade de riqueza, com os homens brancos estando à frente das mulheres brancas. Pessoas negras têm menor probabilidade, estando as mulheres negras em considerável desvantagem em relação aos homens negros. Quando se compara ao que ocorre com relação às desigualdades de renda centradas na média, a disparidade de riqueza intensifica os extremos. Por um lado, as vantagens dos homens brancos são muito mais intensas. Por outro lado, as desvantagens das mulheres negras são muito mais severas.

Resta saber qual o papel exato das desigualdades por áreas de formação na mediação da disparidade de riqueza por raça e gênero. De modo geral, as mulheres são maioria entre as pessoas com curso superior. Mas, quando se considera simultaneamente gênero e raça, as coisas são diferentes na população em estudo. Lideram as mulheres brancas, depois vêm os homens brancos, em seguida as mulheres negras e, seguindo-as de perto, os homens negros. Por outro lado, as mulheres, muito especialmente as mulheres negras, estão sensivelmente concentradas em formações superiores associadas a menores rendimentos. Os gráficos a seguir mostram, para cada um desses quatro grupos, o diagrama de dispersão, associando a sua proporção no público de determinada área de formação ao $90^{\circ}$ quantil de renda do total de pessoas formadas na respectiva área, número que representa aqui o nível de afluência econômica associado à respectiva formação específica. Optou-se por esse número em vez de uma medida de tendência central, como a renda média ou mediana, levando-se em conta que o foco do presente estudo é a riqueza. Mais do que a afluência média, o $90^{\circ}$ quantil representa os níveis mais altos de afluência aos quais determinada formação está associada. De qualquer modo, cabe notar, a 
correlação entre o $90^{\circ}$ quantil e a renda média é quase perfeita, aproximadamente 0,98. Uma diferença substantiva é que os doutores lideram o ordenamento quando se trata de renda média, enquanto os médicos estão no topo em se tratando do $90^{\circ}$ quantil da renda. O objetivo é observar como cada um dos quatro grupos compõe o público das áreas de formação mais ou menos afluentes.

Os homens brancos estão francamente concentrados nas formações mais afluentes. Há um pico em formações alto-intermediárias, entre as quais contam as ciências exatas e as aplicadas ao mundo da produção. Já entre os homens negros, há concentração nas formações de afluência intermediária e alto-intermediária, com uma queda acentuada entre as mais afluentes. A distribuição das mulheres negras aparentemente espelha a distribuição dos homens brancos. O fato é que elas estão altamente concentradas nos cursos menos afluentes. A distribuição das mulheres brancas é, por sua vez, muito diferente. Elas se concentram em cursos de baixa afluência e em áreas de formação com alta concentração feminina em geral, como educação, serviço social e enfermagem. Contudo, elas se recuperam muito nitidamente entre os doutores, assim como nas áreas do direito e da medicina, que estão entre as mais afluentes. Note-se ainda que, ao longo de todas as áreas, as mulheres brancas estão mais presentes que os homens negros em termos absolutos. Isso vale até mesmo para as engenharias, cursos em que os homens, em geral, marcam maior presença.

Gráfico 5.3: Dispersão por áreas de formação das mulheres brancas

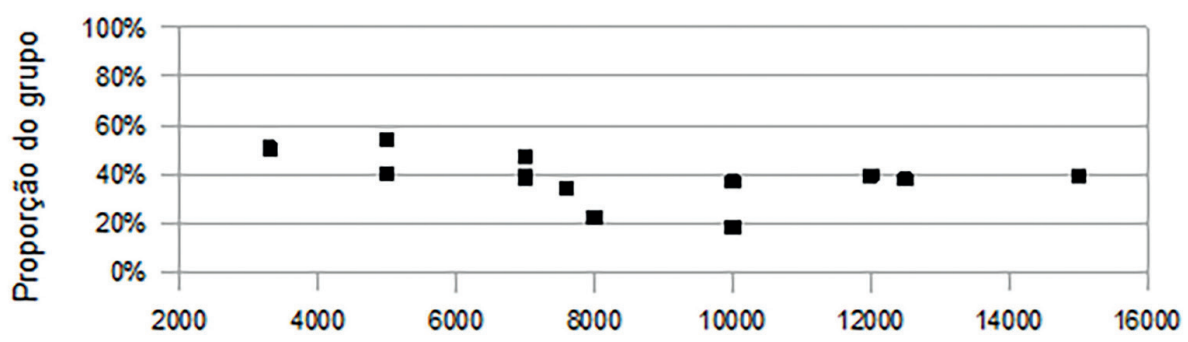

Nonagésimo quantil de renda

Fonte: IBGE - Censo Demográfico 2010 - Microdados. Elaboração própria. 
Gráfico 5.4: Dispersão por áreas de formação dos homens brancos

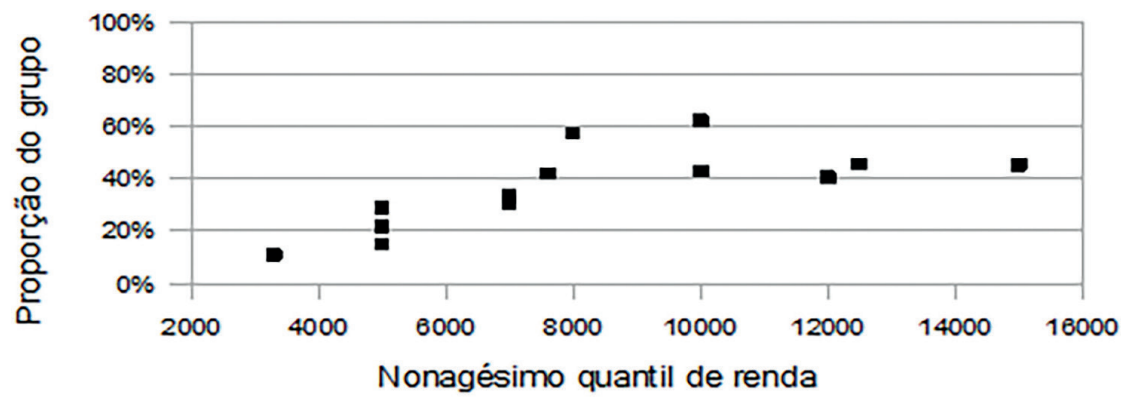

Fonte: IBGE - Censo Demográfico 2010 - Microdados. Elaboração própria.

Gráfico 5.5: Dispersão por áreas de formação das mulheres negras

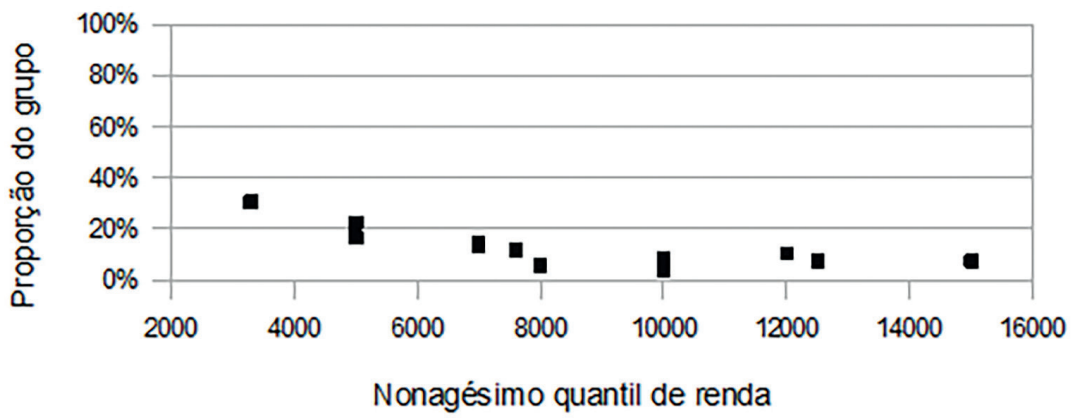

Fonte: IBGE - Censo Demográfico 2010 - Microdados. Elaboração própria.

Gráfico 5.6: Dispersão por áreas de formação dos homens negros

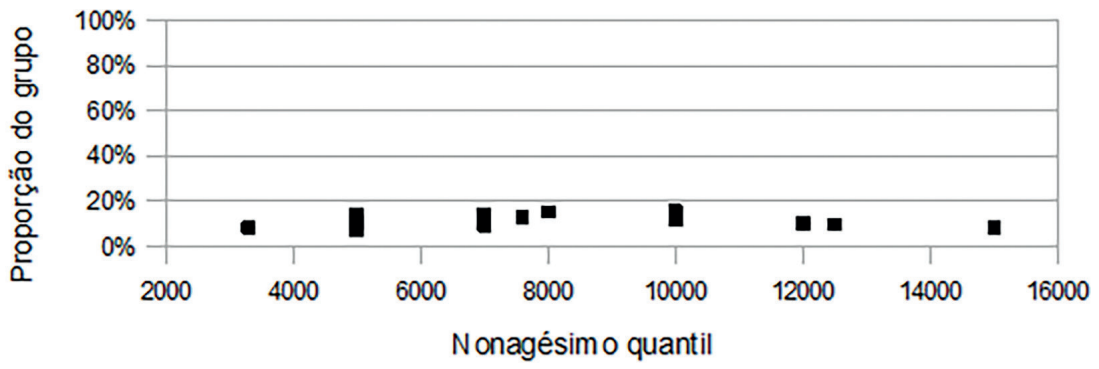

Fonte: IBGE - Censo Demográfico 2010 - Microdados. Elaboração própria. 
A questão a ser respondida é como essa distribuição diferencial, concomitantemente por sexo e por raça, ao longo das áreas de formação medeia a disparidade de riqueza. Observou-se já o comportamento da mediação educacional da disparidade de riqueza segundo a raça e segundo o sexo. Agora, se deseja responder a uma questão posterior: qual o papel das formações específicas nessa mediação? Para tanto, é possível observar o comportamento da disparidade diretamente associada à raça e ao sexo ao longo de três modelos de regressão logística. Um que explica a probabilidade de riqueza em razão da idade e de indicadores de sexo e raça. Um segundo que inclui também indicadores para níveis educacionais, considerando-se o nível superior de ensino como um bloco. E, finalmente, um terceiro que desagrega o nível superior em áreas de formação. Os resultados são apresentados pelo Gráfico 5.7.

Gráfico 5.7: Razão de probabilidades de riqueza para homens e para mulheres com três níveis de controle por educação. Brasil, renda igual ou superior a um salário mínimo, 2010.

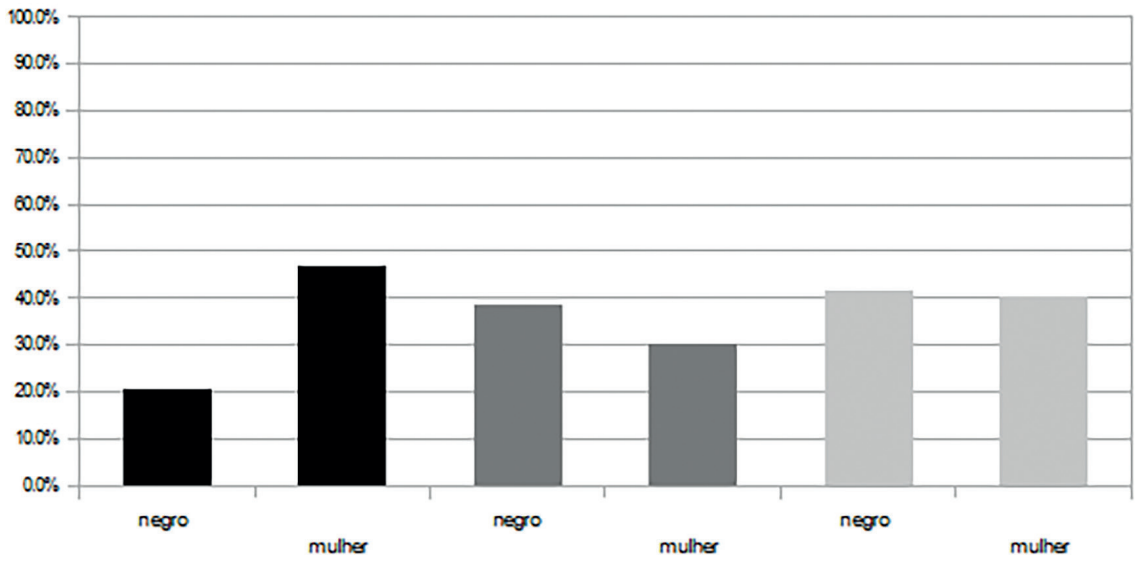

Fonte: IBGE - Censo Demográfico 2010 - Microdados. Elaboração própria.

As últimas duas colunas são familiares. São as mesmas apresentadas no Gráfico 4.1, onde se notou que o desconto da mediação educacional não chega a inverter nitidamente, como o faz em se tratando de rendimentos médios, a ordem de tamanho entre os impactos diretamente associados à raça e ao sexo, respectivamente. O que se deve observar agora é como essas colunas diferem daquelas em cinza mais escuro, que 
representam os resultados do modelo que considera o nível superior de ensino como um bloco. Nota-se que, nesse último caso, há inversão entre gênero e raça. Descontada a mediação educacional, considerando o nível superior de ensino como um bloco, a disparidade de riqueza diretamente associada à raça passa a ser menor que aquela associada diretamente ao gênero. A condição de mulher aparece associada a uma razão de chances menor que aquela associada à condição de negro. Isso acontece porque o desconto da mediação educacional equivale a simular um cenário em que pessoas negras têm os mesmos níveis educacionais que pessoas brancas, o que significa uma elevação educacional dos primeiros. Por outro lado, o mesmo desconto significa simular um cenário em que as mulheres perdem sua vantagem educacional em relação aos homens.

Quando se consideram as áreas de formação, os negros experimentam uma melhoria adicional em suas condições, indo de uma razão de chances de $38 \%$ para 42\%. Já para as mulheres ocorre algo diferente. O segundo modelo representa uma queda na razão de chances, dos 47\% do modelo básico para 30\%. Agora, quando se consideram as formações específicas, há um efeito no sentido inverso, com a razão de chances se recuperando dos $30 \%$ para os $41 \%$. Assim, no cenário hipotético em que mulheres passam a ter a mesma distribuição por áreas de formação que os homens, há um ganho para as mulheres em termos de probabilidades de riqueza.

Essa recuperação não é suficiente para retornar as mulheres aos níveis de disparidade do modelo básico. Em outras palavras, no final, o desconto da mediação educacional continua representando para elas um prejuízo líquido, enquanto representa uma vantagem líquida para pessoas negras. Isso se deve ao fato de que o cenário hipotético beneficia as mulheres pela equiparação das áreas de formação, mas as prejudica pela equiparação dos seus níveis gerais de escolaridade aos dos homens, o que implica descontar as vantagens advindas do seu maior ingresso no nível superior de ensino. O que ocorre é que essa desconsideração das vantagens educacionais globais sobrepuja o desconto das desvantagens em termos de área de formação.

O que se conclui é que a mediação educacional da disparidade racial de riqueza está mais relacionada ao restrito acesso ao nível superior de ensino e mais 
discretamente a diferenças de caráter alocativo no interior desse nível de ensino. Já a mediação educacional da disparidade de riqueza segundo o gênero não se refere ao acesso ao nível superior de ensino que é, na verdade, mais elevado para as mulheres. O que há é uma mediação substancial dada pela distribuição pelas diferentes áreas de formação superior. Embora esse mecanismo de mediação se faça valer também para a disparidade racial, sua relevância é muito maior para a disparidade de gênero. $\mathrm{O}$ desconto dessa fonte de disparidade de riqueza eleva a razão de chances associada à condição de negro dos 38\% para os $42 \%$, uma diferença de quatro pontos percentuais. Já a razão de chances associada à condição de mulher se recupera de 30\% para 41\%, uma diferença quase três vezes maior.

É preciso, no entanto, interpretar esses resultados dando atenção ao caráter dinâmico dos fenômenos em questão. Os diagramas de dispersão apresentados anteriormente atestam nítidas assimetrias por raça da distribuição por áreas de formação. Embora o que mais se observe é a baixa proporção de pessoas negras em todas as áreas, reforçando a ideia de uma mediação dada sobretudo pela restrição ao acesso a esse nível de ensino, observam-se também diferenças de forma. Embora presentes em cursos afluentes hegemonicamente masculinos, os homens negros frequentam muito pouco as áreas de formação mais afluentes. As mulheres negras, por sua vez, estão francamente concentradas nas áreas de formação menos afluentes. Se, no futuro, os níveis de acesso ao ensino superior por parte da população negra se ampliarem e, ao mesmo tempo, se mantiverem esses padrões de distribuição racial pelas áreas de formação, haverá um aumento na relevância dessas áreas enquanto mecanismo de mediação da disparidade racial de riqueza.

Mais uma vez, para observar propriamente a condição da mulher negra, é preciso levar em conta a interação entre sexo e raça. Novamente, isso será feito pela consideração das quatro categorias geradas pela combinação entre esses fatores, tomando-se o grupo dos homens brancos como referência. A questão é como as formações específicas participam da mediação educacional da disparidade de riqueza quando se consideram esses quatro grupos. Se a formação, em geral, é a 
principal mediadora da disparidade de riqueza segundo a raça e a formação específica a principal mediadora segundo o gênero, a hipótese é a de que a mulher negra sofra com intensidade os efeitos desses dois mecanismos. Por meio da extensão da decomposição Oaxaca-Blinder para modelos não lineares, é possível aferir a contribuição dos atributos individuais para a disparidade de riqueza ao longo de diferentes especificações de regressão logística. O que se obtém é uma medida dessa contribuição ao longo de três modelos. Um que explica a probabilidade de riqueza apenas em razão da idade. Um segundo que a explica também em razão dos níveis educacionais de maneira geral, e um terceiro que considera também as diferenças em termos de área de formação. Os resultados são apresentados no Gráfico 5.8.

Gráfico 5.8: Decomposição Oaxaca-Blinder das probabilidades de riqueza para categorias de raça e gênero. Brasil, Sudeste urbano, renda igual ou superior a um salário mínimo, 2010.

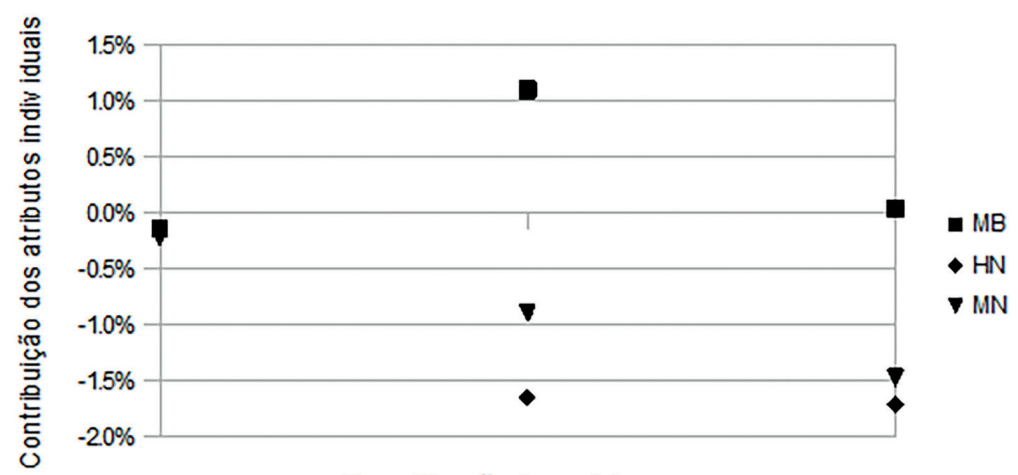

Especificação do modelo

Fonte: IBGE - Censo Demográfico 2010 - Microdados. Elaboração própria.

Quanto mais abaixo de zero, mais o valor indica que os atributos individuais em questão contribuem para a desvantagem do respectivo grupo em relação aos homens brancos. Quando o valor está acima de zero, o caso é o oposto: os atributos em questão reduzem a desvantagem. Por exemplo, os resultados sugerem que os níveis educacionais das mulheres brancas, na segunda especificação do modelo, contribuem para descontar $1 \%$ da diferença que existe entre suas probabilidades de riqueza e a probabilidade de riqueza dos homens brancos. Não obstante essas cifras, dada a inconsistência 
da técnica de decomposição para aferir o tamanho das contribuições, a interpretação deve se ater à variação dessas contribuições estimadas ao longo das diferentes especificações do modelo, desprezando os valores propriamente ditos. A análise deve se ater à forma do gráfico, desconsiderando os níveis dispostos no eixo vertical.

O que se observa são os padrões esperados. Para as mulheres brancas, a educação, em geral, exerce um efeito de redução sobre a disparidade de riqueza, aproximando-as dos homens brancos, mas, quando se consideram as formações específicas, a contribuição se dá no sentido inverso. Para os homens negros, a educação, em geral, contribui muito intensamente para aumentar a disparidade de riqueza, havendo ainda uma contribuição adicional das diferenças por área de formação que é, porém, muito suave. Já para as mulheres negras, a educação, em geral, contribui intensamente para a disparidade e as formações específicas contribuem com intensidade semelhante. O que se conclui é que a mediação educacional da disparidade de riqueza entre mulheres brancas e homens brancos, em desvantagem das primeiras, está exclusivamente em razão de desigualdades em termos de áreas de formação. Para os homens negros, essa mediação está sobretudo em razão dos níveis de acesso ao ensino superior, havendo uma contribuição adicional modesta das áreas de formação. Já no que se refere às mulheres negras, tanto o acesso ao ensino superior quanto a distribuição diferencial por áreas de formação medeiam substancialmente a disparidade de riqueza. É notável que a desigualdade por áreas de formação tenha uma relevância tão substantiva para as mulheres negras mesmo sendo seu acesso ao nível superior de ensino bastante restrito. Isso indica um padrão crítico de concentração em áreas de formação menos afluentes.

\subsection{Conversão da educação em oportunidades de riqueza para as mulheres negras}

Como já foi visto, além das desigualdades educacionais, os diferenciais em termos das condições para a conversão da educação em oportunidades de riqueza 
também têm um peso muito importante na determinação da disparidade racial na composição do grupo dos ricos. Pessoas negras não têm a mesma habilidade que pessoas brancas para converter determinado nível de ensino ou credencial em probabilidades de pertencer a tal grupo. Diante da situação das mulheres, em média mais educadas que os homens e, ao mesmo tempo, com rendimentos mais baixos do que os deles, só se pode esperar que tais condições cumpram um papel fundamental. Se elas são mais educadas e ainda assim menos frequentes entre os ricos, seus níveis educacionais não parecem se converter em probabilidades de riqueza com a mesma facilidade que o fazem para os homens. Nessa seção, será abordado o papel dessas condições na mediação da disparidade de riqueza considerando-se simultaneamente a raça e o sexo das pessoas. A hipótese é a de que, embora, conforme já foi mostrado, essas condições diferenciais sejam altamente relevantes para a disparidade racial, elas cumprem um papel mais saliente na mediação da disparidade de riqueza segundo o gênero. Em comparação com essa última, a disparidade segundo a raça seria mais bem explicada por fatores não observados, além, claro, das desvantagens em níveis educacionais já abordadas na seção anterior. Com isso, espera-se observar uma situação especialmente crítica para a mulher negra, que sofre impactos intensos pelas duas fontes de disparidade, mantendo-se em franca desvantagem diante de todos os outros grupos.

Para testar essa hipótese, recorre-se mais uma vez à técnica de decomposição JMP. Implementa-se um modelo de regressão linear explicando a renda em função da idade e da escolaridade, considerando as diferenças por área de formação. Essa regressão é implementada para os quatro grupos em consideração: homens brancos, mulheres brancas, homens negros e mulheres negras. A população foi mais uma vez restringida ao Sudeste urbano. O exercício é feito de modo a comparar os quatro grupos entre si, tomando-os par a par. Como visto na última aplicação, os resultados dessa decomposição podem variar conforme a escolha do grupo de referência. Contudo, dado o número de comparações em jogo, para tornar a apresentação tratável, optou-se por fazer as comparações em apenas um sentido: imputando as 
características do grupo com maior participação entre os ricos ao grupo com menor participação. Sendo assim, os quatro grupos conformam seis pares de comparação. O objetivo é distinguir, em cada par, o papel desempenhado pelas condições de conversão da educação em oportunidades de riqueza do papel desempenhado por fatores não observados. A Tabela 5.4 apresenta os resultados desse exercício.

Tabela 5.4: Simulações JMP para a participação no grupo dos ricos por raça e sexo. Brasil, Sudeste urbano, renda igual ou superior a um salário mínimo, 2010.

\begin{tabular}{|c|c|c|c|c|}
\hline & $\begin{array}{l}\text { Homem } \\
\text { branco }\end{array}$ & $\begin{array}{l}\text { Mulher } \\
\text { branca }\end{array}$ & $\begin{array}{c}\text { Homem } \\
\text { negro }\end{array}$ & $\begin{array}{c}\text { Mulher } \\
\text { negra }\end{array}$ \\
\hline Mulher branca & $\begin{array}{c}22,6 \% \text { *** } \\
31,2 \% \text { ** } \\
40,1 \% \text { * }\end{array}$ & - & - & - \\
\hline Homem negro & $\begin{array}{c}7,5 \text { *** } \\
15,1 \% \text { ** } \\
21,0 \% \text { * }\end{array}$ & $\begin{array}{c}7,5 \% \text { *** } \\
13,8 \% \text { ** } \\
8,3 \% \text { * }\end{array}$ & - & - \\
\hline Mulher negra & $\begin{array}{l}2,1 \% \text { *** } \\
4,3 \% \text { ** } \\
17,7 \% \text { * }\end{array}$ & $\begin{array}{c}2,1 \% \text { *** } \\
3,7 \% \text { ** } \\
6,1 \% \text { * }\end{array}$ & $\begin{array}{c}2,1 \% \text { *** } \\
2,2 \% \text { ** } \\
4,6 \% \text { * }\end{array}$ & - \\
\hline
\end{tabular}

*** Proporção entre os ricos na distribuição real ** Proporção entre os ricos com atribuição de resíduos * Proporção entre os ricos com atribuição de resíduos e de coeficientes

Fonte: IBGE - Censo Demográfico 2010 - Microdados. Elaboração própria.

Os grupos em vantagem estão dispostos em linha, e os em desvantagem, em coluna. Assim, às mulheres brancas são imputadas apenas as características dos homens brancos. Aos homens negros são imputadas as características dos homens e das mulheres brancas, posto que ambos os grupos estão em vantagem sobre eles quanto às chances de riqueza. Às mulheres negras são imputadas as características de todos os outros grupos. Nenhum dos pares possíveis deixa de ser comparado, embora a comparação se dê de modo unilateral no que se refere à imputação de características. Embora as comparações sejam feitas par a par, as proporções são computadas considerando o total de ricos. Por exemplo, quando se imputa às mulheres negras as condições dos homens brancos, calcula-se a 
proporção resultante de mulheres negras não apenas com relação aos homens brancos, mas considerando também os outros dois grupos.

Observe-se, primeiramente, a comparação entre mulheres brancas e homens brancos. A atribuição da distribuição dos resíduos desses últimos aumenta consideravelmente a participação dessas mulheres no grupo dos ricos, elevando-a de $22 \%$ para 31\%, aproximadamente. A atribuição dos coeficientes exerce um efeito muito semelhante, elevando a participação das mulheres brancas entre os ricos de 31\% para $40 \%$. Isso quer dizer que, por relação aos homens brancos, fatores não observados e as condições para a conversão da educação e da experiência em oportunidades de riqueza cumprem um papel semelhante na mediação da disparidade de riqueza.

Quando se compara os homens negros aos homens brancos, a atribuição aos primeiros da distribuição de resíduos dos últimos exerce um forte impacto. A participação dos primeiros dobra, indo de 7,5\% a 15,1\%. A atribuição dos coeficientes implica uma mudança também considerável, elevando a participação esperada dos homens negros entre os ricos dos 15,1\% para os 21\%. Da diferença total de 13,4\% que separa a participação inicial e aquela que resulta da imputação de coeficientes e de fatores não observados, 56\% se devem à atribuição dos resíduos e 44\% à atribuição de coeficientes.

Quando se compara a mulher negra ao homem branco, nota-se, mais uma vez, um impacto expressivo dos fatores não observados, que elevam de 2,1\% para 4,3\% a participação dessas mulheres entre os ricos. Os efeitos da atribuição dos coeficientes são, contudo, bem mais expressivos, elevando a participação de 4,3\% a 17,7\%. Da diferença global de 15,6\% exercida pelas simulações, 85\% se devem à atribuição dos coeficientes, denotando uma relevância sobrepujante das condições para a conversão de educação em oportunidades de riqueza na mediação da disparidade.

Quando se compara o homem negro à mulher branca, nota-se, de modo semelhante ao que ocorre na comparação entre esses e os homens brancos, um forte impacto da imputação de fatores não observados que praticamente dobra a participação dos homens negros no grupo dos ricos, levando-a de 7,5\% a 13,8\%. 
A atribuição dos coeficientes, contudo, exerce efeito oposto, reduzindo a participação dos homens negros a 8,3\%, trazendo-a para um nível próximo ao inicial. O que isso mostra é que, em comparação com as mulheres brancas, as condições para a conversão da educação em oportunidades de riqueza antes favorecem o homem negro. Já os fatores não observados de mediação exercem um efeito desfavorável e, importante notar, sobrepujante.

Comparando-se agora a mulher negra à mulher branca, nota-se que a imputação de resíduos eleva a participação das negras de 2,1\% para 3,7\%. Já a imputação dos coeficientes faz uma diferença maior, elevando a participação de 3,7\% para $6,1 \%$. Assim, da diferença total de quatro pontos percentuais, os coeficientes respondem por aproximadamente $60 \%$. Nota-se, portanto, a maior saliência dos coeficientes na determinação da disparidade entre mulheres negras e mulheres brancas. Assim, embora em termos de condições para a conversão da educação em oportunidades de riqueza os homens negros não estejam em desvantagem, mas sim em vantagem em relação às mulheres brancas, as mulheres negras estão em grande desvantagem. Tanto os resíduos quanto os coeficientes favorecem as mulheres brancas em relação às mulheres negras.

Finalmente, tem-se a comparação entre mulheres negras e homens negros. A imputação dos fatores não observados exerce agora um efeito muito discreto, elevando de 2,1\% para 2,2\% a participação das mulheres negras no grupo dos ricos. Já a imputação dos coeficientes exerce um impacto mais expressivo, elevando a participação de 2,2\% para 4,6\%. Assim, a atribuição dos coeficientes responde por $94 \%$ da diferença total de 2,5\% decorrente das simulações. As condições diferenciais para a conversão da educação em oportunidades de riqueza respondem, portanto, quase que exclusivamente pela disparidade entre homens e mulheres negras.

Observando os efeitos das diferentes simulações com o grupo das mulheres negras, nota-se nitidamente o grau da hierarquia entre os diferentes grupos. A atribuição da situação dos homens brancos às mulheres negras eleva a sua participação ao patamar de quase $18 \%$. Já a atribuição das condições das mulheres 
brancas eleva essa participação a apenas 6\%. Por sua vez, a atribuição a elas das condições dos homens negros eleva sua participação a modestos 4,6\%. Como se nota, as condições dos homens brancos superam largamente as condições de todos os outros grupos, enquanto as condições das mulheres brancas superam as dos homens negros em grau consideravelmente menor. Por fim, para que se tenha uma ideia do quão desfavoráveis são as condições enfrentadas pelas mulheres negras, vale mencionar um cenário não apresentado na Tabela 4.4: a imputação da sua situação aos homens brancos rebaixaria sua participação de $68 \%$ dos ricos para apenas 15\%. Mesmo as mulheres brancas, grupo com os melhores níveis de escolaridade e, portanto, o mais resistente à redução dos níveis de riqueza mediante esses exercícios de simulação, sofreriam uma queda de representatividade dos seus aproximados $23 \%$ para apenas $4 \%$.

O que se conclui é que a primeira hipótese, a de que as condições para a conversão da educação e da experiência em oportunidades de riqueza opera prioritariamente em razão do gênero, confirma-se. Mulheres brancas não contam com condições desfavoráveis apenas em relação aos homens brancos, mas também em relação aos homens negros. Em comparação com esses últimos, contudo, elas contam com ampla vantagem no que se refere a fatores não observados, e o peso desses últimos supera o das desvantagens expressas pelos coeficientes, impondo uma vantagem líquida. A mulher negra também sofre desvantagens em termos das condições para a conversão da educação em chances de riqueza não apenas diante do homem branco como também diante do homem negro. Trata-se de uma desvantagem muito expressiva, aliás, como atestam as contribuições de mais de $80 \%$, em ambos os casos, da atribuição dos coeficientes para a diferença total exercida pelas simulações.

Essa maior saliência das condições diferenciais em razão do gênero não quer dizer, contudo, que essas condições não variem muito fortemente também em razão da condição racial. Diante dos homens brancos, a desvantagem dos homens negros em termos dessas condições é apenas um pouco menor que a desvantagem em termos de fatores não observados. Mais ainda, quando se trata de comparar as 
mulheres negras às mulheres brancas, $60 \%$ da diferença total exercida pelas simulações se deve aos coeficientes. Assim, se o homem negro tem vantagem sobre a mulher branca no que se refere às condições de conversão da educação em chances de riqueza, a mulher negra sofre grande desvantagem. Em absolutamente todos os pares de comparação, as mulheres negras encontram-se em desvantagem em razão das duas fontes de disparidade de riqueza consideradas, confirmando a ideia de que a simultaneidade dos fatores raça e gênero configura uma condição única em termos de restrição das chances de vida.

\subsection{O papel da formação superior específica}

No segundo capítulo, discutiu-se amplamente a perspectiva teórica da acomodação das relações raciais a posições de classe. Notou-se que a própria ausência de negros entre os ricos pode ser bem compreendida sob esse prisma. Mais ainda, a hipótese mais tentadora derivada dessa abordagem enuncia que a desigualdade diretamente associada à condição racial é tanto maior quanto mais elevados forem os níveis socioeconômicos em questão. Verificou-se esse padrão considerando-se o comportamento da desigualdade racial ao longo da distribuição de renda. Quanto mais elevados os níveis de rendimento, maior a desigualdade entre negros e brancos. Isso não apenas em razão dos menores níveis de escolaridade da população negra, os quais reduzem seu acesso justamente às posições mais altas. Sobretudo, as desvantagens diretamente associadas à condição racial são tão maiores quanto mais elevados os patamares de renda considerados.

Estará a mediação da desigualdade racial pelas áreas de formação relacionada a esse fenômeno? Colocando de outro modo: as áreas de formação mais afluentes estariam associadas a maiores níveis de desigualdade racial, de modo a reforçar o padrão observado no terceiro capítulo deste livro? Como já se observou no presente capítulo, parte da disparidade racial de riqueza é mediada pela desigualdade educacional em termos de áreas de formação. Será que áreas de formação especialmente 
associadas à riqueza, além de incluírem proporções menores de pessoas negras, estão associadas a maiores níveis de disparidade racial na composição do grupo dos ricos? Com efeito, a desigualdade racial de renda varia de acordo com as áreas de formação superior em questão. Em outras palavras, agrupando-se pessoas segundo as suas respectivas áreas, observam-se níveis de desigualdade racial de renda muito distintos no interior de cada um desses grupos. Será que essa variação segue o padrão de maior disparidade para áreas de formação associadas à maior afluência econômica?

Para testar essa hipótese, utiliza-se, mais uma vez, um modelo logístico em que a probabilidade de riqueza é dada em razão da idade, da educação e da condição racial, incluindo-se um termo de interação entre condição racial e educação. Para controlar por fatores de segmentação geográfica, a amostra é, mais uma vez, restringida a pessoas residentes em áreas urbanas do Sudeste, sendo os resultados consistentes com os obtidos para populações de outras regiões e de áreas rurais. Homens e mulheres são tratados em conjunto.

Para mensurar a disparidade racial de riqueza, opta-se, como nas seções anteriores, pela razão entre as probabilidades que negros e brancos têm de estarem no grupo dos ricos. Considere-se, por um lado, a probabilidade de riqueza associada a cada área de formação e, por outro lado, a razão entre as probabilidades de riqueza de negros e de brancos, condicionais à respectiva área. O Gráfico 5.9 mostra o diagrama de dispersão para essas duas quantidades.

Nitidamente, quanto maior a associação entre uma área de formação e a riqueza, menor é, em termos relativos, a disparidade racial de riqueza condicional à respectiva área, contrariando a hipótese. A reta indica a tendência central nesse sentido. Por sua vez, a dispersão em torno da reta indica diferenças mais específicas. Direito e medicina se destacam como áreas associadas a menores níveis de disparidade racial, com razões de probabilidade em torno de ou superiores a 80\%. Por outro lado, os doutores, assim como o grupo que inclui as engenharias, a arquitetura e a computação, revelam-se fortemente associados à riqueza, mantendo, por outro lado, associação com níveis mais drásticos de disparidade racial. Tem-se os médicos e, em 
seguida, os doutores como aqueles com maior probabilidade de riqueza. Contudo, enquanto a razão de probabilidades entre negros e brancos associada à medicina é de $85 \%$, aquela associada ao doutorado é de $71 \%$. Seguem o direito e as engenharias em níveis de associação com a riqueza, sendo que a razão de probabilidades entre negros e brancos é de $79 \%$ entre os primeiros e de $49 \%$ entre os segundos. Isso mostra que, além da associação entre nível de afluência e disparidade racial de riqueza condicional às áreas de formação, existem características próprias a determinados campos de atuação que os fazem menos desiguais. Medicina e direito mostram níveis de disparidade inferiores aos de áreas de formação com níveis de afluência equiparáveis, o que indica que, no meio dos profissionais liberais, a disparidade racial tende a ser menor.

Gráfico 5.9: Diagrama de dispersão: disparidade racial de riqueza condicional às áreas de formação pela probabilidade de riqueza condicional à respectiva área

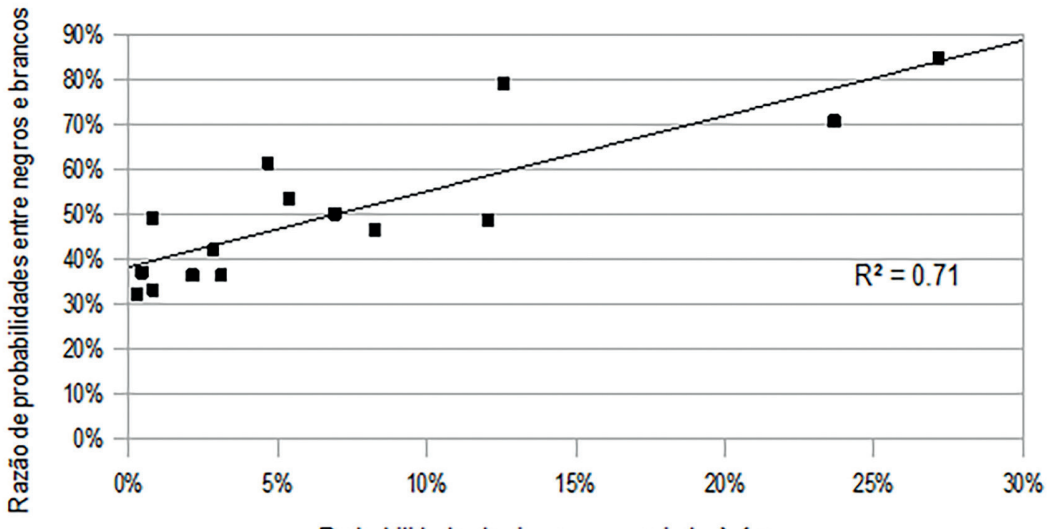

Probabilidade de riqueza associada à área

Fonte: IBGE - Censo Demográfico 2010 - Microdados. Elaboração própria.

A tendência linear revela que o padrão de acomodação das relações raciais em posições de classe não se manifesta na mediação da relação entre raça e riqueza por formações específicas. Fosse esse o caso, os cursos mais fortemente associados à riqueza deveriam apresentar também maiores níveis de disparidade racial. Esse fato é muito significativo, pois revela que a educação de elite tem um grande potencial 
para a correção da disparidade racial de riqueza. Como já se notou, uma porção moderada dessa disparidade é explicada por desigualdades educacionais. Notou-se também que, dessa porção, a maior parte se deve a desigualdades educacionais de maneira geral, quer dizer: mais à pouca presença de negros nos níveis superiores de ensino do que à distribuição racialmente desigual ao longo das áreas de formação. Contudo, a discreta contribuição das desigualdades em termos de educação específica não deve ser menosprezada. Se ela é pequena, é porque a grande barreira ainda está no acesso ao nível superior de ensino. À medida que mais negros atingirem esse nível, a desigualdade por áreas de formação passará a ser mais e mais relevante.

Diante desse cenário, a relação linear entre associação com a riqueza e menores níveis de disparidade racial condicional concede à educação especializada um papel de destaque na correção da disparidade racial de riqueza. As pessoas negras que recebem educação de elite não apenas se deparam com maiores chances de riqueza em termos absolutos, mas também com chances mais igualitárias perante as pessoas brancas. Portanto, o aumento em frequência de negros nas formações mais afluentes não ataca a disparidade racial de riqueza apenas pela equalização dos níveis educacionais, mas também pela equiparação das próprias condições para a conversão da educação em oportunidades de riqueza, uma vez que, de maneira geral, as formações de elite são justamente aquelas em que essas condições parecem ser menos desiguais.

Ressalve-se, contudo, que a relação linear encontrada não deixa de ser em alguma medida artificiosa. À medida que as probabilidades de riqueza crescem, a razão tende a ser menor para uma mesma diferença absoluta. Por exemplo, na área das humanidades, a probabilidade de negros serem ricos é de 0,9\% e a dos brancos é de 2,6\%. A diferença absoluta é de 1,7 ponto percentual, e a razão, de 0,35, apontando forte desigualdade. Na área do direito, a probabilidade para os negros é de $10 \%$, e para os brancos, de $13 \%$. Nesse caso, a diferença absoluta é maior 3 pontos percentuais, mas a razão é de 0,77 , apontando menor desigualdade. É importante notar, portanto, que o padrão linear se refere estritamente a uma 
medida de desigualdade relativa nas probabilidades de riqueza, e que o uso dessa medida insere, no contexto do presente exercício, certa artificialidade. O uso da medida de desigualdade absoluta levaria a resultados diferentes. Por outro lado, no contexto deste livro, tem-se trabalhado com medidas de desigualdade baseadas em razões. Isso vale para os exercícios com regressões lineares, onde a escala logarítmica implica trabalhar com razões na escala "natural” de renda. Vale também para os exercícios com regressão logística, onde se trabalha com razões entre probabilidades. Assim, a opção, na presente seção, pela medida de desigualdade relativa justifica-se, quando nada, por manter coerência com os resultados anteriores, com os quais ela é posta em diálogo neste capítulo.

\subsection{Conclusão}

A maior parte das hipóteses lançadas neste capítulo foram confirmadas ou qualificadas pela discussão de resultados mais detalhados. A hipótese de que a desigualdade em níveis educacionais medeia mais discretamente a desigualdade racial em se tratando da composição do grupo dos ricos se confirma. Diretamente relacionada está a segunda hipótese, de um papel mais proeminente das condições diferenciais para a conversão da educação em oportunidades de riqueza. Com efeito, essas condições parecem cumprir um papel tão importante quanto o da própria desigualdade educacional. Notou-se que esse resultado depende de escolhas operacionais eminentemente arbitrárias, mas que, de qualquer modo, mesmo considerando-se a opção que mais subestima o papel dessas condições, sua relevância é muito considerável.

A hipótese de que a disparidade de riqueza apresenta um quadro crítico no que se refere à mulher negra, graças à articulação entre raça e gênero, recebeu amplo suporte. Primeiramente, notou-se que a relação entre raça, gênero e riqueza difere da relação entre raça, gênero e desigualdade de renda aferida em torno da média. Notou-se que o desconto da mediação educacional não inverte, como o faz no que se refere à desigualdade entre rendas médias, a ordem de relevância das 
desvantagens diretamente associadas ao gênero e à raça. Se a razão de chances de riqueza associada à condição de mulher é muito mais favorável que aquela associada à condição de negro num modelo de regressão básico, o controle pelas desigualdades educacionais não inverte a ordem desses fatores de maneira considerável. Notou-se também que essa não inversão depende da distribuição desfavorável das mulheres pelas diferentes áreas de formação. Quando se considera apenas o nível superior como um bloco, os maiores níveis globais de escolaridade das mulheres prevalecem e o desconto dessa vantagem rebaixa suas razões de chance de riqueza para aquém daquelas associadas à condição de negro. Já quando se consideram as diferenças por áreas específicas de formação, as vantagens das mulheres em termos de níveis globais de escolaridade são, em certa medida, contrabalançadas pelas desvantagens alocativas no nível superior de ensino. Passam a ser menores, então, as vantagens educacionais que se descontam delas por meio do controle estatístico. É apenas nessa situação que a inversão entre raça e gênero não acontece quando a mediação educacional da disparidade de riqueza é descontada.

Ao considerar-se a interação entre raça e gênero, revelaram-se as condições críticas enfrentadas pelas mulheres negras. Quanto à mediação educacional da disparidade de riqueza, elas sofrem, enquanto negras, de menores níveis educacionais de maneira global e, enquanto mulheres negras (mulheres brancas têm ampla presença em certas áreas de formação afluentes), de franca concentração em áreas pouco afluentes. Já no que se refere às condições para a conversão da educação em oportunidades de riqueza, as mulheres negras estão em desvantagem diante de todos os outros grupos. O mesmo não acontece com os homens negros, que estão em vantagem diante das mulheres brancas, ainda que essa vantagem seja sobrepujada pelas desvantagens em termos de fatores não observados. Também no que diz respeito a esses fatores, as mulheres negras estão em desvantagem diante de todos os outros grupos. Em suma, todos os mecanismos de mediação da disparidade de riqueza agem indistintamente em desfavor das mulheres negras. A única exceção é sua vantagem em termos de níveis educacionais diante do homem negro, a qual não se confirma, contudo, em 
termos de áreas de formação específica e que, de qualquer modo, não faz frente às desvantagens massivas em termos das outras fontes de disparidade.

Finalmente, a hipótese de que a disparidade racial de riqueza condicional às áreas de formação obedece ao padrão de acomodação das relações raciais em posições de classe é refutada. Observa-se, na verdade, o fenômeno oposto, com a disparidade racial de riqueza sendo tão menor quanto maiores as probabilidades de riqueza associadas a determinada área de formação. Muito importante notar, há também diferenças em termos de desigualdade racial relativa entre áreas com níveis semelhantes de afluência. Observa-se maior equidade condicional às áreas de formação das profissões liberais. Isso sugere que a variação da desigualdade racial ao longo das diferentes áreas de formação está relacionada às características dos setores do mercado de trabalho para os quais elas estão voltadas. Os critérios de recrutamento, os processos de seleção envolvidos, tudo isso afeta o quanto a competição em determinado setor da atividade econômica está aberta a processos de discriminação racial direta afetos aos níveis de rendimento das pessoas. 